\title{
Synthesis, Characterization and Antimicrobial Evaluation of Newly Synthesized Compounds With Phthalimide Skeleton
}

\author{
Kamelia Amin ${ }^{1}$, Afaf El-Masry², Neama Mohamed ${ }^{2}$, Ghada Awad ${ }^{3}$ and Basma \\ Habib $^{2, *}$ \\ ${ }^{1}$ Department of Pharmaceutical Chemistry, Faculty of Pharmacy, Cairo University, \\ ${ }^{2}$ Department of Therapeutical Chemistry and ${ }^{3}$ Department of Natural and Microbial \\ Products, National Research Centre, Cairo, Egypt.
}

\begin{abstract}
TN AN EFFORT to develop new antimicrobial agents, a novel series of 2-\{[4-(substituted phenyl)amino]methyl)-1 $H$-isoindole-1,3(2H)-dione derivatives (2-17a,b) was synthesized starting from 2-(\{[4-(bromoacetyl)phenyl]amino $\}$ methyl)-1H-isoindole-1,3(2H)-dione (1) by introducing different heterocyclic moieties, such as thiazole, thiazolidinone, azetidinone, furan and pyrazole. The structures of all the synthesized compounds have been elucidated by means of IR, ${ }^{1} \mathrm{H}$ NMR, mass spectroscopic data and elemental analysis. Most of the synthesized compounds were screened for their antimicrobial activity by means of agar well diffusion assay while the minimal inhibitory concentrations of the active compounds were then assessed utilizing broth dilution method. Derivative 2-[(4-\{[(1,3-Dioxo-1,3-dihydro- $2 H$-isoindol-2-yl) methyl]amino phenyl)-2-oxoethyl]propane dinitrile (15) was the most potent compound.
\end{abstract}

Keywords: Phthalimide, Heterocyclic derivatives, Thiazole, Antibacterial agents, Antifungal agents.

\section{Introduction}

Phthalimide containing compounds have attracted the interest of scientists since the thalidomide incidence in the middle of the last century [1]. Furthermore, many literatures have investigated the phthalimide derivatives due to their diverse range of biological activities such as antimicrobial [2-5], antiviral [6,7], anticancer [8,9], anti-inflammatory $[10,11]$, antiepileptic[12,13], antihyperlipidimic $[14,15]$, antihyperglycemic [16], anxiolytic [17], etc.

Microbial infectious diseases are one of the most serious global problems and represent major socio-economic challenge facing humanity. One of its complications is the development of antimicrobial resistance (AMR) as a consequence of misuse of the antimicrobial medicines or when a microorganism mutates or acquires a resistance gene. A World Health Organization report in 2014 stated that we are already facing this major threat in every region of the world. Thus, the discovery of new antimicrobial agents is an urgent need to overcome the threat of the resistant microbes.

In the view of these observation, it was of interest to synthesize several $2-\{[4-($ substituted phenyl)amino]methyl)- $1 H$-isoindole-1,3(2H)dione derivatives and screen them for their antimicrobial activities.

\section{Results and Discussion}

\section{Chemistry}

In this study, we synthesized a series of phthalimide derivatives based on 2-(\{[4-(bromoacetyl)phenyl]amino $\}$ methyl)$1 H$-isoindole-1,3(2H)-dione (1) as a key starting material. Compound 1 was synthesized by treatment of the compound A namely $2-\{[(4-$ Acetylphenyl)amino $]$ methyl $\}-1 H$ isoindole-1,3(2H)-dione with bromine water in the presence of glacial acetic acid as a reacting medium at room temperature.

The treatment of $\alpha$-bromoketone (1) with thiourea in absolute ethanol via Hantzsch thiazole synthesis yielded 1,3-thiazole derivative (2). Condensation of compound 2 with different aldehydes, aromatic aldehydes or monosaccharide, in ethanol with the presence of basic catalyst gave Schiff bases $3(4 a, b)$. The cyclization of Schiff bases $(4 a, b)$ with thioglycolic acid in dioxane at room temperature afforded the thiazolidin-4-one derivatives 
$(5 \mathrm{a}, \mathrm{b})$. Furthermore, condensation of the amino derivative (2) with several anhydrides, namely, succinic, maleic and phthalic anhydride in glacial acetic acid under reflux yielded the pyrrole derivatives (6a-c), respectively. (Scheme 1)

Similar to the synthesis of derivative (2), the hydrazino-thiazole derivative (7) was synthesized via condensation of key substance (1) with thiosemicarbazide.
The condensation of compound 7 with different aromatic aldehydes gave Schiff's bases (8a-d). Staudinger synthesis was used for the preparation of the azetidin-2-ones $(9 \mathrm{a}, \mathrm{b})$ and their 3-chloro derivatives $(10 \mathrm{a}, \mathrm{b})$ by reacting compounds $8 \mathrm{a}, \mathrm{c}$ with acetyl chloride and chloroacetyl chloride, respectively. While the formation of thiazolidinone derivatives (11a,b, 12a,b) was achieved via reaction of the imine derivatives $(8 b, d)$ with thioglycolic acid and/or thiolactic acid, respectively (Scheme 2).

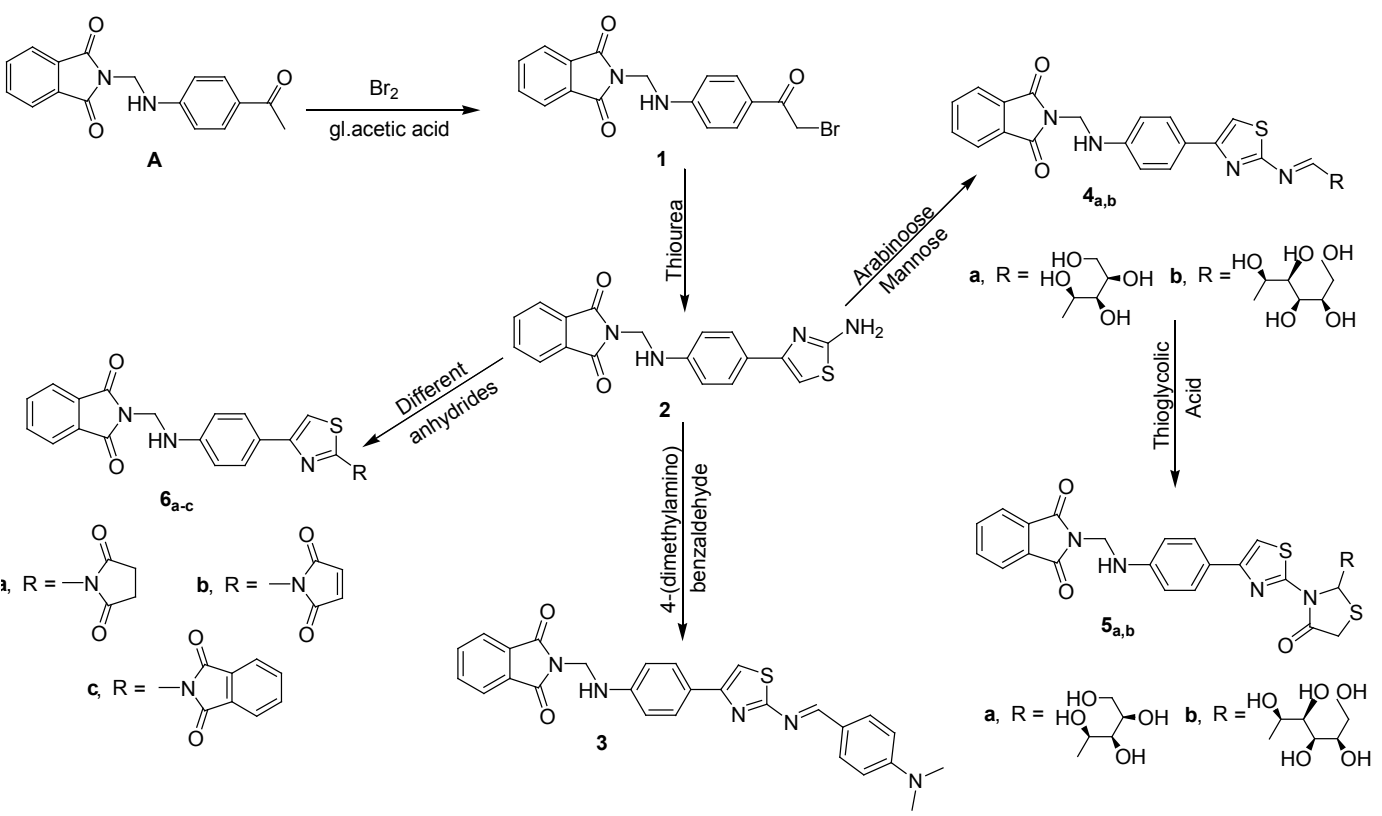

Scheme 1
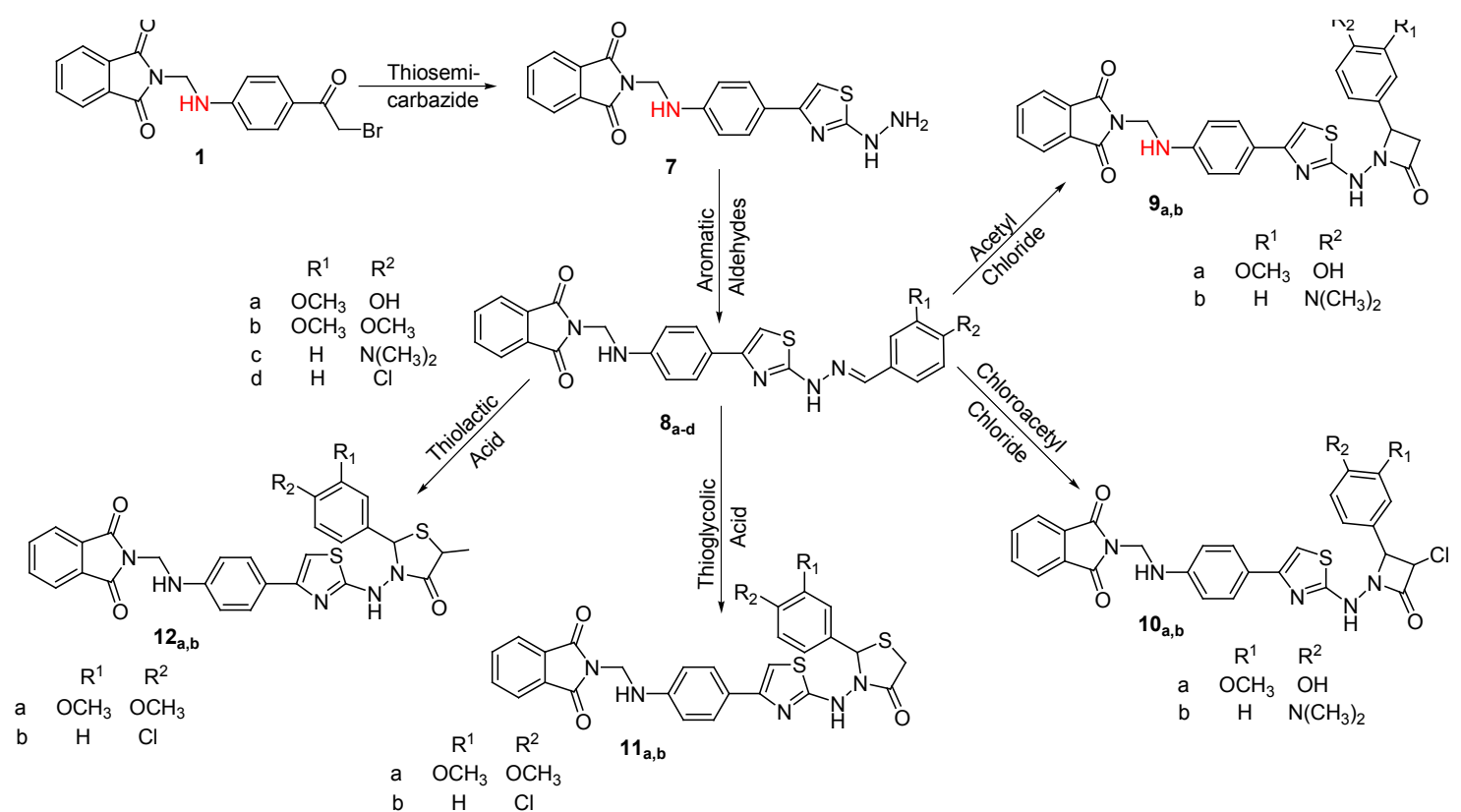

Scheme 2 
On the other hand, compound 1 was refluxed with selenium dioxide in absolute ethanol to afford ethyl 2-oxoacetate derivative (13) after the removal of the selenium metal, which on reacting with o-phenylenediamine gave the phthalimido quinoxalinone derivative (14).

Treatment of bromoacetyl compound 1 with malononitrile in ethanolic solution containing sodium hydroxide afforded the new isoindolyl dinitrile derivative (15). Compound 15 was then cyclized using acetic acid and concentrated hydrochloric acid gave 2-amino furan-3carbonitrile derivative (16). While on reacting compound 15 with hydrazine hydrate or phenyl hydrazine in ethanolic solution furnished the diaminopyrazole derivatives (17a,b) (Scheme 3).<smiles>CCOC(=O)C(=O)c1ccc(NCN2C(=O)c3ccccc3C2=O)cc1</smiles>

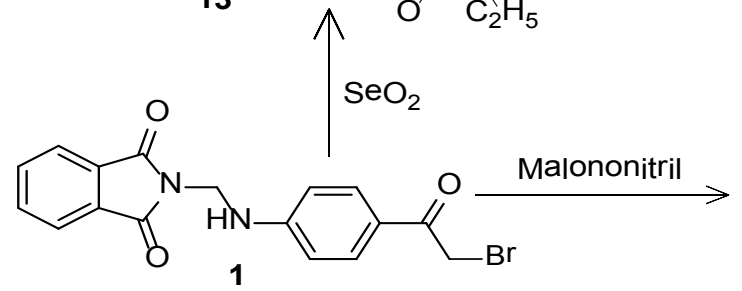<smiles>N#CC(C#N)CC(=O)c1ccc(NCN2C(=O)c3ccccc3C2=O)cc1</smiles><smiles>Nc1n[nH]c(N)c1CC(=O)c1ccc(NCN2C(=O)c3ccccc3C2=O)cc1</smiles>

a, $\mathrm{R}=\mathrm{H}$ $17_{a, b}$

b, $\mathrm{R}=$ phenyl

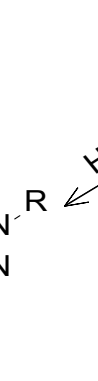
$\mathrm{R}$<smiles>N#CC1CC1[R]1CC1</smiles><smiles>N#Cc1cc(-c2ccc(NCN3C(=O)c4ccccc4C3=O)cc2)oc1N</smiles>

16

Scheme 3

\section{Antimicrobial results}

In this work, 22 newly synthesized compounds (1, 2, 3, 4b, 5a,b, 6b,c, 7, 8a,b,d, 9a,b, 10a,b, 11a, $12 \mathrm{a}, 14,15,16$ and $17 \mathrm{a})$ were screened for their in vitro antibacterial and antifungal activities by using the agar well diffusion and broth dilution methods against a panel of Gram positive bacteria [Staphylococcus aureus ATCC9213, Bacillus subtilis ATCC6633, Bacillus megaterium ATCC9885], Gram negative bacteria [Klebsiella pneumoniae ATCC13883, Pseudomonas aeruginosa ATCC27953, Escherichia coli ATCC25922], Fungi [Saccharomyces cerevisiae, Candida albicans NRRLY-477, Aspergillus niger Local isolate]. Ciprofloxacin and Ketoconazole were the reference drugs used in the evaluation of the antibacterial and antifungal activity of the tested compounds, respectively.

Based on the results recorded in Tables 1 \& 2 and expressed in terms of IZ and MIC, the antibacterial and antifungal activities of the newly synthesized compounds in comparison to the used standard drugs, Ciprofloxacin and Ketoconazole, respectively, clarified that most of the compound tested showed IZ and MIC ranging from 39 to $12 \mathrm{~mm}$ and from 25 to $200 \mu \mathrm{g} / \mathrm{ml}$, respectively. Substantially, most of the tested compounds showed remarkable activity against the Gram negative bacteria and were active against the fungi. The bacteria were less susceptible to their antibacterial effect, while the $A$. niger was the most resistible microorganism. While, $K$. pneumonia and $S$. cerevisiae were the most sensitive bacterium and fungus, respectively.

Thekeyintermediate, bromo-acetyl(compound 1) was moderately active against bacteria and yeast but no activity against $S$. aureus and $A$. niger. In contrast, its amino thiazole derivative (2) showed good antifungal activity especially against $A$. niger but lower antibacterial activity. The other tested phthalimide-thiazole derivatives exerted diversity in their activity, Schiff's base 
TABLE 1. Antimicrobial activity of compounds 1 - 17a expressed as diameter of inhibition zones (mm) against the pathological strains based on well diffusion assay".

\begin{tabular}{|c|c|c|c|c|c|c|c|c|c|}
\hline \multirow[b]{2}{*}{$\begin{array}{c}\text { Tested } \\
\text { compounds }\end{array}$} & \multicolumn{3}{|c|}{ Gram positive bacteria } & \multicolumn{3}{|c|}{ Gram negative bacteria } & \multicolumn{3}{|c|}{ Fungi } \\
\hline & 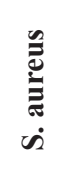 & 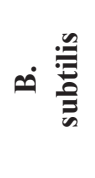 & ص & 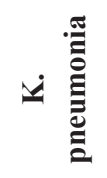 & 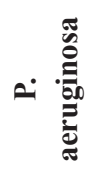 & ن & $\dot{\infty} \stackrel{\frac{\pi}{2}}{\frac{\pi}{2}}$ & ن & 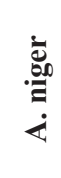 \\
\hline 1 & 15 & 25 & 22 & 23 & 22 & 21 & 24 & 20 & -ve \\
\hline 2 & -ve & 25 & 15 & 26 & 16 & 21 & 25 & 24 & 25 \\
\hline 3 & 12 & 19 & 13 & 20 & 26 & 18 & 20 & 17 & -ve \\
\hline $4 b$ & 25 & 21 & 28 & 30 & 26 & 30 & 30 & 25 & 28 \\
\hline $5 a$ & -ve & 18 & 13 & 24 & 16 & 20 & 20 & -ve & -ve \\
\hline $5 b$ & 20 & 20 & 18 & 21 & 27 & 21 & 21 & 18 & -ve \\
\hline $6 b$ & 15 & -ve & 16 & 26 & 18 & 21 & 20 & 16 & 17 \\
\hline $6 c$ & 16 & 17 & 16 & 19 & 17 & 17 & 20 & 18 & -ve \\
\hline 7 & -ve & 18 & 16 & 25 & 18 & 16 & 26 & -ve & -ve \\
\hline $8 \mathrm{a}$ & -ve & -ve & -ve & 28 & 24 & 19 & 28 & -ve & -ve \\
\hline $8 \mathrm{~b}$ & 16 & -ve & 16 & 23 & 22 & 17 & 19 & 16 & -ve \\
\hline $8 \mathrm{~d}$ & 18 & 16 & 19 & 19 & 18 & 19 & 17 & 15 & 20 \\
\hline $9 \mathrm{a}$ & 25 & 15 & 27 & 20 & 21 & 17 & 12 & 22 & -ve \\
\hline $9 b$ & 18 & 14 & 15 & 19 & 20 & 19 & 19 & 15 & 30 \\
\hline $10 \mathrm{a}$ & 18 & 19 & 18 & 20 & 19 & 19 & 15 & 20 & -ve \\
\hline $10 \mathrm{~b}$ & 20 & 17 & 18 & 22 & 20 & 22 & 22 & 23 & 18 \\
\hline $11 \mathrm{a}$ & -ve & -ve & 16 & 26 & 19 & 26 & 18 & 16 & -ve \\
\hline $12 \mathrm{a}$ & 20 & 21 & 20 & 21 & 20 & 16 & 14 & 14 & -ve \\
\hline 14 & -ve & -ve & 14 & 18 & 16 & 22 & 23 & 22 & 25 \\
\hline 15 & 38 & 39 & 38 & 38 & 39 & 37 & 33 & 31 & 28 \\
\hline 16 & 15 & 15 & 15 & 17 & 18 & 20 & 15 & 14 & -ve \\
\hline $17 \mathrm{a}$ & -ve & -ve & 16 & 21 & 16 & 19 & 30 & 30 & -ve \\
\hline Ciprofloxacin & 20 & 22 & 24 & 25 & 24 & 23 & -ve & -ve & -ve \\
\hline Ketoconazole & -ve & -ve & -ve & -ve & -ve & -ve & 23 & 22 & 24 \\
\hline
\end{tabular}

*The experiment was carried out in triplicate and the average zone of inhibition was calculated; N.A. (no activity).

Egypt. J. Chem. 60, No.4 (2017) 
TABLE 2. Minimum inhibitory concentration $(\mu \mathrm{g} / \mathrm{ml})$ of compounds $1-17$ a against the pathological strains based on two fold serial dilution technique.

\begin{tabular}{|c|c|c|c|c|c|c|c|c|c|}
\hline \multirow[b]{2}{*}{$\begin{array}{l}\text { Tested } \\
\text { compounds }\end{array}$} & \multicolumn{3}{|c|}{ Gram positive bacteria } & \multicolumn{3}{|c|}{ Gram negative bacteria } & \multicolumn{3}{|c|}{ Fungi } \\
\hline & $\dot{\omega}$ & 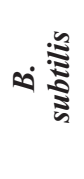 & 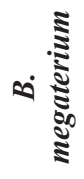 & 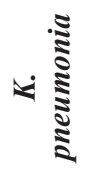 & 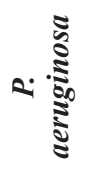 & $\underset{8}{3}$ & ن & ن & 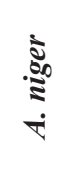 \\
\hline 1 & - & 100 & 100 & 100 & 100 & 200 & 50 & 200 & - \\
\hline 2 & - & 100 & - & 100 & 200 & 200 & 100 & 100 & 50 \\
\hline 3 & - & 200 & - & 200 & 50 & 200 & 200 & 200 & - \\
\hline $4 b$ & 50 & 200 & 50 & 25 & 100 & 50 & 50 & 100 & 50 \\
\hline $5 \mathrm{a}$ & - & - & - & 50 & 200 & 200 & 200 & - & - \\
\hline $5 b$ & 100 & 200 & 200 & 100 & 50 & 200 & 200 & 200 & - \\
\hline $6 b$ & - & - & 200 & 100 & 200 & 100 & 200 & 200 & 200 \\
\hline $6 \mathrm{c}$ & 200 & 200 & 200 & 200 & 200 & 200 & 200 & 200 & - \\
\hline 7 & - & - & - & 50 & 200 & 200 & 100 & - & - \\
\hline $8 \mathrm{a}$ & - & - & - & 50 & 50 & 200 & 100 & - & - \\
\hline $8 b$ & 200 & - & 200 & 100 & 100 & 200 & 200 & 200 & - \\
\hline $8 \mathrm{~d}$ & 200 & 200 & 200 & 200 & 200 & 200 & 200 & - & 200 \\
\hline $9 \mathrm{a}$ & 50 & - & 50 & 200 & 200 & 200 & - & 200 & - \\
\hline $9 b$ & 200 & - & - & 200 & 200 & 200 & 200 & - & 50 \\
\hline $10 \mathrm{a}$ & 200 & 200 & 200 & 100 & 200 & 200 & - & 200 & - \\
\hline $10 \mathrm{~b}$ & 100 & 200 & 200 & 100 & 200 & 200 & 100 & 100 & 200 \\
\hline $11 \mathrm{a}$ & - & - & 200 & 50 & 200 & 50 & 200 & - & - \\
\hline $12 \mathrm{a}$ & 100 & 100 & 100 & 100 & 200 & 200 & - & - & - \\
\hline 14 & - & - & - & 200 & 200 & 100 & 100 & 100 & 50 \\
\hline 15 & 25 & 25 & 25 & 25 & 25 & 25 & 25 & 25 & 25 \\
\hline 16 & - & - & - & 200 & 200 & 200 & - & - & - \\
\hline $17 \mathrm{a}$ & - & - & 200 & 200 & 200 & 200 & 50 & 50 & - \\
\hline Ciprofloxacin & 20 & 22 & 24 & 25 & 24 & 23 & -ve & $-\mathrm{ve}$ & -ve \\
\hline Ketoconazole & -ve & -ve & -ve & -ve & -ve & -ve & 23 & 22 & 24 \\
\hline
\end{tabular}


(3) showed insignificant antimicrobial activity. The thiazole Schiff's base (4b), containing sugar moeity, possessed remarkable antimicrobial activity ( $\mathrm{MIC}=25-200 \mu \mathrm{g} / \mathrm{ml}$ ) which was higher than the parent amino thiazole derivative (2), while its corresponding thiazolidinone derivative (5b) showed moderate activity. However the thiazole azetidine (10b) and thiazolidinone (12a) were also active against the tested pathogens, but they only showed weak to moderate activity (MIC $=100$ $200 \mu \mathrm{g} / \mathrm{ml}$ ). While, the thiazolidinone derivative (12a) had no antifungal activity.

Unpredictably, the quinoxaline derivative (14) exhibited good antifungal activity particularly against $\mathrm{A}$. niger $(\mathrm{MIC}=50 \mu \mathrm{g} / \mathrm{ml})$. In addition, the dinitrile compound 15 showed prominent antimicrobial activity $(\mathrm{MIC}=25 \mu \mathrm{g} / \mathrm{ml})$ against all the test pathogens. The cyanofuran derivative 16 exhibited poor activity (MIC $=200 \mu \mathrm{g} / \mathrm{ml}$ ) against the used Gram negative bacteria, while diaminopyrazole derivative $17 \mathrm{a}$ exhibited good antifungal activity ( $\mathrm{MIC}=50 \mu \mathrm{g} / \mathrm{ml}$ ) against $S$. cervesia and $C$. albicans and weak antibacterial effects $(\mathrm{MIC}=200 \mu \mathrm{g} / \mathrm{ml})$.

In conclusion, a total of 22 novel phthalimide compounds were subjected to antimicrobial screening. From the tested phthalimide derivatives, the dinitrile derivative (15), showed promising antimicrobial activity ( $\mathrm{MIC}=25 \mu \mathrm{g} / \mathrm{ml}$ ) against all tested microorganisms and can be regarded as promising lead structures for development of enhanced antimicrobial candidates. Two other derivatives, thiazole derivative $4 \mathrm{~b}$ and azetidinone derivative (10c), were moderately active as antimicrobial agents $(\mathrm{MIC}=25-200 \mu \mathrm{g} / \mathrm{ml})$.

\section{Materials and Methods}

\section{Chemistry}

Melting points were determined using an electro-thermal capillary melting point apparatus and remained uncorrected. Microanalyses were carried out at the Micro Analytical Center, Cairo University. Infrared spectra were acquired with a Jasco FT/IR-6100 using $\mathrm{KBr}$ discs. ${ }^{1} \mathrm{H}$ NMR spectra were acquired with Jeol EX $500 \mathrm{MHz}$ spectrometers, using TMS as internal standard. Mass spectra were acquired with a Jeol JMS-AX 500. All reactions were followed and checked by TLC (aluminium-backed sheets, Merck plates) with chloroform-methanol 9:1 (v/v) as a mobile phase, the spots were detected by exposure to UV analysis lamp $\lambda 254 / 366 \mathrm{~nm}$ for few seconds. Iodine vapor was used for the detection of the plates.
$2-\{[(4-$ Acetylphenyl)amino $]$ methyl $\}-1 H$ isoindole-1,3(2H)-dione $(A)$

This compound was prepared according to the reported method [18].

Preparation of 2-(\{[4-(Bromoacetyl)phenyl] amino\}methyl)-1H-isoindole-1,3(2H)-dione (1)

To a solution of compound A $(0.74 \mathrm{~g}, 2.5$ $\mathrm{mmol})$ in glacial acetic acid $(10 \mathrm{ml})$, bromine water $(1 \mathrm{ml})$ was added dropwise with vigorous stirring during $1 / 2 \mathrm{hr}$. The reaction mixture was kept overnight and then poured on crushed ice. The separated product was filtered off, washed several times with water, vacuum dried and crystallized from isopropanol, light yellow crystals (Scheme 1), mp 109-111 ${ }^{\circ} \mathrm{C}$, yeild $72 \%$, Analysis for $\mathrm{C}_{17} \mathrm{H}_{13} \mathrm{BrN}_{2} \mathrm{O}_{3}$, M.Wt. 372.01, calculated C: 54.71 $\mathrm{H}: 3.51 \mathrm{~N}: 7.51$, found: $\mathrm{C}: 54.49 \mathrm{H}: 3.72 \mathrm{~N}: 7.65$. IR $\left(\mathrm{KBr} ; \mathrm{cm}^{-1}\right): 3373(\mathrm{NH}), 3025\left(\mathrm{CH}_{\text {aromatic }}\right), 2925$ $\left(\mathrm{CH}_{\text {aliphatic }}\right), 1769,1712,1671(3 \mathrm{C}=\mathrm{O}) .{ }^{1} \mathrm{H}$ NMR (DMSO, $\delta \mathrm{ppm}): 4.93\left(2 \mathrm{H}, \mathrm{s}, \mathrm{CH}_{2} \mathrm{Br}\right), 5.11(2 \mathrm{H}$, $\left.\mathrm{s}, \mathrm{CH}_{2}\right), 7.73-8.28\left(8 \mathrm{H}, \mathrm{m}, \mathrm{H}_{\text {aromatic }}\right), 9.53(1 \mathrm{H}, \mathrm{s}$, $\mathrm{NH})$. MS: $(\mathrm{m} / \mathrm{z}) \sim[\mathrm{M}+1]^{+} 373(18 \%), 375(19 \%)$.

Preparation of 2-(\{[4-(2-Amino-1,3-thiazol-4-yl) phenyl]amino, methyl)-1H-isoindole-1,3(2H)dione (2)

A mixture of compound $1(0.75 \mathrm{~g}, 2 \mathrm{mmol})$ and thiourea $(0.15 \mathrm{~g}, 2 \mathrm{mmol})$ in absolute ethanol $(15 \mathrm{ml})$ was heated under reflux for 3 $\mathrm{hr}$. The reaction mixture was cooled, poured onto ice water and the formed precipitate was filtered off, washed several times with water and vacuum dried, the formed powder was then crystallized from benzene/ethanol $(10 \mathrm{ml} / 0.5$ $\mathrm{ml}$ ), dark yellow crystals (Scheme 1), mp 167-9 ${ }^{\circ} \mathrm{C}$, yield $84 \%$, Analysis for $\mathrm{C}_{18} \mathrm{H}_{14} \mathrm{~N}_{4} \mathrm{O}_{2} \mathrm{~S}$, M.Wt. 350.08, calculated: C: $61.70 \mathrm{H}: 4.03 \mathrm{~N}: 15.99 \mathrm{~S}$ : 9.15, found: C: $61.85 \mathrm{H}: 4.27 \mathrm{~N}: 16.20 \mathrm{~S}: 8.78$. IR $\left(\mathrm{KBr} ; \mathrm{cm}^{-1}\right)$ : 3445, $3346\left(\mathrm{NH}, \mathrm{NH}_{2}\right), 3064$ $\left(\mathrm{CH}_{\text {aromatic }}\right), 2926\left(\mathrm{CH}_{\text {aliphatic }}\right), 1770,1712(2 \mathrm{C}=\mathrm{O})$, $1611(\mathrm{C}=\mathrm{N}) .{ }^{1} \mathrm{H}$ NMR (DMSO, $\left.\delta \mathrm{ppm}\right): 5.10(2 \mathrm{H}$, $\left.\mathrm{s}, \mathrm{CH}_{2}\right), 7.10-8.03\left(9 \mathrm{H}, \mathrm{m}, \mathrm{H}_{\text {aromatic }}, \mathrm{H}_{\text {thiazole }}\right), 6.12$, $9.14\left(3 \mathrm{H}, 2 \mathrm{~s}, \mathrm{NH}_{2}, \mathrm{NH}\right.$ exchangeable with $\left.\mathrm{D}_{2} \mathrm{O}\right)$. MS: $(\mathrm{m} / \mathrm{z}) \sim[\mathrm{M}+1]^{+} 351(32.3 \%), 349$ (61.6\%).

Preparation of 2-(\{[4-(2-\{[(4-Dimethylaminophenyl) methylidene] amino\}-1,3-thiazol4-yl) phenyl] amino;methyl)-1H-isoindole-1,3 (2H)-dione (3)

A mixture of equimolecular amounts of compound $2(0.35 \mathrm{~g}, 1 \mathrm{mmol})$ and 4-dimethylamino-benzaldehyde ( $0.15 \mathrm{~g}, 1 \mathrm{mmol})$ in absolute ethanol $(15 \mathrm{ml})$ was heated under reflux for $18 \mathrm{hr}$. The formed solid was filtered off, air dried and crystallized from acetone, greenish 
brown crystals (Scheme 1), mp 102-4 ${ }^{\circ} \mathrm{C}$, yield 67\%. Analysis: for $\mathrm{C}_{27} \mathrm{H}_{23} \mathrm{~N}_{5} \mathrm{O}_{2} \mathrm{~S}$, M.Wt. 481.16, calculated: $\mathrm{C}: 67.34 \mathrm{H}: 4.81 \mathrm{~N}: 14.54 \mathrm{~S}: 6.66$ found: $\mathrm{C}: 67.72 \mathrm{H}: 4.95 \mathrm{~N}: 14.33 \mathrm{~S}: 6.91$. IR $\left(\mathrm{KBr} ; \mathrm{cm}^{-1}\right): 3358(\mathrm{NH}), 3045\left(\mathrm{CH}_{\text {aromatic }}\right), 2915$ $\left(\mathrm{CH}_{\text {aliphatic }}\right), 1769,1716(2 \mathrm{C}=\mathrm{O}), 1594(\mathrm{C}=\mathrm{N}) \cdot{ }^{1} \mathrm{H}$ NMR (DMSO, $\delta$ ppm): $3.00\left(6 \mathrm{H}, \mathrm{s}, 2 \mathrm{CH}_{3}\right), 5.21$ $\left(2 \mathrm{H}, \mathrm{s}, \mathrm{CH}_{2}\right), 6.74-7.95\left(14 \mathrm{H}, \mathrm{m}, \mathrm{H}_{\text {aromatic }}, \mathrm{CH}=\mathrm{N}\right.$, $\left.\mathrm{H}_{\text {thiazole }}\right), 9.62\left(1 \mathrm{H}, \mathrm{s}, \mathrm{NH}\right.$ exchangeable with $\left.\mathrm{D}_{2} \mathrm{O}\right)$. MS: $(\mathrm{m} / \mathrm{z}) \sim[\mathrm{M}+1]^{+} 482(2 \%)$.

General procedure for preparation of compounds $(4 a, b)$

A mixture of compound $2(0.35 \mathrm{~g}, 1 \mathrm{mmol})$ dissolved in absolute ethanol $(5 \mathrm{ml})$ and dimethylformamide $(0.5 \mathrm{ml})$ and the respective monosaccaride, namely, D-arabinose or D-mannose (1 mmol) dissolved in the least amount of water and containing few drops of glacial acetic acid was heated on water bath at $60^{\circ} \mathrm{C}$ for $7-10 \mathrm{hr}$. After cooling, the separated solid was filtered off, washed with water followed by cold ethanol and then dried to give compounds $4 \mathrm{a}, \mathrm{b}$, respectively (Scheme 1).

2-(\{[4-(2-\{[2,3,4,5-Tetrahydroxypentylidene] amino\}-1,3-thiazol-4-yl)phenyl]amino\} methyl)1 H-isoindole-1,3(2H)-dione (4a)

Crystallized from ethanol, greenish yellow crystals, mp 142-3 ${ }^{\circ} \mathrm{C}$, yield $70 \%$. Analysis: for $\mathrm{C}_{23} \mathrm{H}_{22} \mathrm{~N}_{4} \mathrm{O}_{6} \mathrm{~S}$, M.Wt. 482.13, calculated: C: $57.25 \mathrm{H}$ : $4.60 \mathrm{~N}: 11.61 \mathrm{~S}: 6.65$ found: C: $57.43 \mathrm{H}: 4.79 \mathrm{~N}: 11.83$ S: 6.45. IR (KBr; $\left.\mathrm{cm}^{-1}\right)$ : 3675-3209 (4OH), 3365 $(\mathrm{NH}), 3045\left(\mathrm{CH}_{\text {aromatic }}\right), 2923\left(\mathrm{CH}_{\text {aliphatic }}\right), 1770,1711$ $(2 \mathrm{C}=\mathrm{O}), 1610(\mathrm{C}=\mathrm{N}) .{ }^{1} \mathrm{H}$ NMR (DMSO, $\left.\delta \mathrm{ppm}\right)$ : 2.55-2.89 (4H, m, 4OH), 3.38-3.87 (5H, m, 3CH, $\left.\mathrm{CH}_{2}\right), 5.18\left(2 \mathrm{H}, \mathrm{s}, \mathrm{CH}_{2}\right), 6.92-8.14\left(10 \mathrm{H}, \mathrm{m}, \mathrm{H}_{\text {aromatic}}\right.$, $\left.\mathrm{CH}=\mathrm{N}, \mathrm{H}_{\text {thiazole }}\right), 8.95(1 \mathrm{H}, \mathrm{s}, \mathrm{NH}$ exchangeable with D 2 ). MS: $(\mathrm{m} / \mathrm{z}) \sim[\mathrm{M}]^{+} 482(5.9 \%)$.

2-(\{[4-(2-\{[2,3,4,5,6-Pentahydroxyhexylidene] amino\}-1,3-thiazol-4-yl)phenyl]amino\} methyl)1H-isoindole-1,3(2H)-dione (4b)

Crystallized from ethanol, greenish yellow crystals, mp 154-6 ${ }^{\circ} \mathrm{C}$, yield $62 \%$. Analysis: for $\mathrm{C}_{24} \mathrm{H}_{24} \mathrm{~N}_{4} \mathrm{O}_{7} \mathrm{~S}$, M.Wt. 512.14, calculated: C: $56.24 \mathrm{H}: 4.72 \mathrm{~N}: 10.93 \mathrm{~S}: 6.26$ found: $\mathrm{C}: 56.65$ $\mathrm{H}: 4.56 \mathrm{~N}: 11.08 \mathrm{~S}: 6.52$. IR $\left(\mathrm{KBr} ; \mathrm{cm}^{-1}\right)$ : $3647-$ $3221(4 \mathrm{OH}), 3365(\mathrm{NH}), 3045\left(\mathrm{CH}_{\text {aromatic }}\right), 2923$ $\left(\mathrm{CH}_{\text {aliphatic }}\right), 1770,1711(2 \mathrm{C}=\mathrm{O}), 1610(\mathrm{C}=\mathrm{N}) \cdot{ }^{1} \mathrm{H}$ NMR (DMSO, $\delta$ ppm): 2.73-2.89 (5H, m, 5OH), 3.32-3.83 (6H, m, 4CH, $\left.\mathrm{CH}_{2}\right), 5.22\left(2 \mathrm{H}, \mathrm{s}, \mathrm{CH}_{2}\right)$, 6.96-8.14 (10H, m, $\left.\mathrm{H}_{\text {aromatic }}, \mathrm{CH}=\mathrm{N}, \mathrm{H}_{\text {thizole }}\right), 8.97$ $\left(1 \mathrm{H}, \mathrm{s}, \mathrm{NH}\right.$ exchangeable with $\left.\mathrm{D}_{2} \mathrm{O}\right)$. MS: $(\mathrm{m} / \mathrm{z}) \sim$ $[\mathrm{M}]^{+} 512(3.1 \%)$.
General procedure for preparation of compounds $(5 a, b)$

A solution of compounds $4 \mathrm{a}, \mathrm{b}(4 \mathrm{mmol})$ and thioglycolic acid $(0.6 \mathrm{ml}, 8 \mathrm{mmol})$ in dioxane $(10$ $\mathrm{ml}$ ) was stirred at room temperature for 10-12 hr. The solvent was evaporated and the residue was washed with sodium carbonate solution $(4 \mathrm{~N})$ then with water. The separated solid was filtered off, washed with water till carbonate-free then cold ethanol then ether and dried under vacuum at room temperature to give the corresponding compounds 5a,b, respectively (Scheme 1).

$2-\{[(4-\{2-[4-o x o-2-(1,2,3,4-$ tetrahydroxybutyl)-1,3-thiazolidin-3-yl]-1,3thiazol-4-yl\} phenyl) amino] methyl\}-1Hisoindole-1,3(2H)-dione (5a)

Crystallized from acetic acid, dark yellow crystals, mp $173-5{ }^{\circ} \mathrm{C}$, yield $65 \%$. Analysis: for $\mathrm{C}_{23} \mathrm{H}_{22} \mathrm{~N}_{4} \mathrm{O}_{6} \mathrm{~S}$ M.Wt. 556.13, calculated: C: 53.95 $\mathrm{H}: 4.35 \mathrm{~N}$ : $10.07 \mathrm{~S}: 11.52$ found: C: $54.22 \mathrm{H}$ : $4.51 \mathrm{~N}: 10.21 \mathrm{~S}: 11.67$. IR $\left(\mathrm{KBr} ; \mathrm{cm}^{-1}\right)$ : 3652$3275(4 \mathrm{OH}), 3436(\mathrm{NH}), 3095\left(\mathrm{CH}_{\text {aromatic }}\right), 2927$ $\left(\mathrm{CH}_{\text {aliphatic }}\right), 1771,1714,1665(3 \mathrm{C}=\mathrm{O}), 1611$ $(\mathrm{C}=\mathrm{N}) .{ }^{1} \mathrm{H}$ NMR (DMSO, $\left.\delta \mathrm{ppm}\right): 2.52-2.63(4 \mathrm{H}$, $\mathrm{m}, 4 \mathrm{OH}), 3.45-4.61\left(7 \mathrm{H}, \mathrm{m}, 3 \mathrm{CH}, 2 \mathrm{CH}_{2}\right), 5.14$ $\left(2 \mathrm{H}, \mathrm{s}, \mathrm{CH}_{2}\right), 6.15(1 \mathrm{H}, \mathrm{s}, \mathrm{CH}$ of thiazolidinone), 6.92-8.20 (9H, m, $\left.\mathrm{H}_{\text {aromatic }}, \mathrm{H}_{\text {thiazole }}\right), 8.95(1 \mathrm{H}, \mathrm{s}$, $\mathrm{NH}$ exchangeable with $\mathrm{D}_{2} \mathrm{O}$ ).

$2-\{[(4-\{2-[4-O x o-2-(1,2,3,4,5-p e n t a h y-$ droxypentyl)-1,3-thiazolidin-3-yl]-1,3-thiazol-4$y l$ l phenyl) amino] methyl\} -1H-isoindole -1,3 (2H)-dione (5b)

Crystallized from acetic acid, dark yellow crystals, mp $175-8{ }^{\circ} \mathrm{C}$, yield $60 \%$. Analysis: for $\mathrm{C}_{26} \mathrm{H}_{26} \mathrm{~N}_{4} \mathrm{O}_{8} \mathrm{~S}_{2}$ M.Wt. 586.12, calculated: C: 53.23 H: $4.47 \mathrm{~N}: 9.55 \mathrm{~S}: 10.96$ found: C: $53.16 \mathrm{H}: 4.78$ $\mathrm{N}: 9.58 \mathrm{~S}: 11.23$. IR $\left(\mathrm{KBr} ; \mathrm{cm}^{-1}\right): 3658-3216(5 \mathrm{OH})$, $3446(\mathrm{NH}), 3095\left(\mathrm{CH}_{\text {aromatic }}\right), 2924\left(\mathrm{CH}_{\text {aliphatic }}\right), 1770$, $1711,1656(3 \mathrm{C}=\mathrm{O}), 1610(\mathrm{C}=\mathrm{N}) .{ }^{1} \mathrm{H}$ NMR (DMSO, $\delta$ ppm): 2.49-2.68 (5H, m, 5OH), 3.43-4.38 (8H, m, $\left.4 \mathrm{CH}, 2 \mathrm{CH}_{2}\right), 5.14\left(2 \mathrm{H}, \mathrm{s}, \mathrm{CH}_{2}\right), 6.14(1 \mathrm{H}, \mathrm{s}, \mathrm{CH}$ of thiazolidinone), 6.89-8.16 (9H, m, $\left.\mathrm{H}_{\text {aromatic }}, \mathrm{H}_{\text {thiazole }}\right)$, $8.67\left(1 \mathrm{H}, \mathrm{s}, \mathrm{NH}\right.$ exchangeable with $\left.\mathrm{D}_{2} \mathrm{O}\right)$.

General procedure for preparation of compounds (6a-c)

A mixture of compound $2(0.35 \mathrm{~g}, 1 \mathrm{mmol})$ and appropriate acid anhydrides, namely, succinic anhydride, maleic anhydride and/or phthalic anhydride $(1 \mathrm{mmol})$ in glacial acetic acid $(12 \mathrm{ml})$ was heated under reflux for $8 \mathrm{hr}$. The reaction mixture was then cooled, poured on ice water, filtered off and air dried to give compounds 6a-c, respectively (Scheme 1).

Egypt. J. Chem. 60, No.4 (2017) 
$2-[(\{4-[2-(2,5-D i o x o p y r r o l i d i n-1-y l)-1,3-$ thiazol-4-yl]phenyl\}amino)methyl]-1H-isoindole1,3(2H)-dione (6a)

Crystallized from ethanol, dark green crystals, mp $124-5{ }^{\circ} \mathrm{C}$, yield $55 \%$. Analysis: for $\mathrm{C}_{22} \mathrm{H}_{16} \mathrm{~N}_{4} \mathrm{O}_{4} \mathrm{~S}$ M.Wt. 432.09, calculated: C: 61.10 H: 3.73 N: 12.96 S: 7.41 found: C: 61.30 H: 3.89 $\mathrm{N}: 12.76 \mathrm{~S}:$ 7.74. IR $\left(\mathrm{KBr} ; \mathrm{cm}^{-1}\right): 3365(\mathrm{NH}), 3015$ $\left(\mathrm{CH}_{\text {aromatic }}\right), 2926\left(\mathrm{CH}_{\text {alinhatic }}\right), 1771,1709(4 \mathrm{C}=\mathrm{O})$, $1593(\mathrm{C}=\mathrm{N}) .{ }^{1} \mathrm{H}$ NMR $(\mathrm{DMSO}, \delta \mathrm{ppm}): 2.11(2 \mathrm{H}$, $\mathrm{t}, \mathrm{CH}_{2}$ Succinimide $), 2.46\left(2 \mathrm{H}, \mathrm{t}, \mathrm{CH}_{2}\right.$ Succinimide $), 5.10$ $\left(2 \mathrm{H}, \mathrm{s}, \mathrm{CH}_{2}\right), 6.74-7.93\left(9 \mathrm{H}, \mathrm{m}, \mathrm{H}_{\text {aromatic }}, \mathrm{H}_{\text {thiazole }}\right)$, $9.86\left(1 \mathrm{H}, \mathrm{s}, \mathrm{NH}\right.$ exchangeable with $\left.\mathrm{D}_{2} \mathrm{O}\right)$. MS: $(\mathrm{m} / \mathrm{z}) \sim[\mathrm{M}]^{+} 432(5.6 \%)$.

2-[(\{4-[2-(2,5-Dioxo-2,5-dihydro-1H-pyrrol1-yl)-1,3-thiazol-4-yl]phenyl?amino) methyl]1H-isoindole-1,3(2H)-dione (6b)

Crystallized from methanol, dark green crystals, mp $132-4{ }^{\circ} \mathrm{C}$, yield $65 \%$. Analysis: for $\mathrm{C}_{22} \mathrm{H}_{14} \mathrm{~N}_{4} \mathrm{O}_{4}$ S M.Wt. 430.07, calculated: C: 61.39 H: $3.28 \mathrm{~N}: 13.02 \mathrm{~S}: 7.45$ found: C: $61.54 \mathrm{H}: 3.55$ $\mathrm{N}: 12.75 \mathrm{~S}: 7.51 . \mathrm{IR}\left(\mathrm{KBr} ; \mathrm{cm}^{-1}\right): 3358(\mathrm{NH}), 3039$ $\left(\mathrm{CH}_{\text {aromatic }}\right), 2919\left(\mathrm{CH}_{\text {aliphatic }}\right), 1772,1714(4 \mathrm{C}=\mathrm{O})$, $1593(\mathrm{C}=\mathrm{N}) .{ }^{1} \mathrm{H}$ NMR (DMSO, $\left.\delta \mathrm{ppm}\right): 5.14(2 \mathrm{H}$, $\left.\mathrm{s}, \mathrm{CH}_{2}\right), 6.67-8.19\left(11 \mathrm{H}, \mathrm{m}, \mathrm{H}_{\text {aromatic }}, \mathrm{H}_{\text {maleimide, }}\right.$ $\left.\mathrm{H}_{\text {thiazole }}\right), 9.14\left(1 \mathrm{H}, \mathrm{s}, \mathrm{NH}\right.$ exchangeable with $\left.\mathrm{D}_{2} \mathrm{O}\right)$. MS: $(\mathrm{m} / \mathrm{z}) \sim[\mathrm{M}]^{+} 430(28.6 \%)$.

$2-[4-(4-\{[(1,3-$ dioxo-1,3-dihydro- $2 \mathrm{H}$ isoindol-2-yl)methyl]amino\} phenyl)-1,3-thiazol2-yl]-1H-isoindole-1,3(2H)-dione (6c)

Crystallized from methanol, brownish green crystals, mp $129-32{ }^{\circ} \mathrm{C}$, yield $65 \%$. Analysis: for $\mathrm{C}_{26} \mathrm{H}_{16} \mathrm{~N}_{4} \mathrm{O}_{4} \mathrm{~S}$, M.Wt. 480.09 , calculated: C: 64.99 H: $3.36 \mathrm{~N}: 11.66 \mathrm{~S}: 6.67$ found: C: $65.31 \mathrm{H}: 3.64$ $\mathrm{N}: 11.39 \mathrm{~S}: 6.89$. IR $\left(\mathrm{KBr} ; \mathrm{cm}^{-1}\right): 3358(\mathrm{NH}), 3036$ $\left(\mathrm{CH}_{\text {aromatic }}\right), 2923\left(\mathrm{CH}_{\text {aliphatic }}\right), 1774,1719(4 \mathrm{C}=\mathrm{O})$, $1611(\mathrm{C}=\mathrm{N}) .{ }^{1} \mathrm{H}$ NMR (DMSO, $\left.\delta \mathrm{ppm}\right): 5.23(2 \mathrm{H}$, $\left.\mathrm{s}, \mathrm{CH}_{2}\right), 6.80-7.95\left(13 \mathrm{H}, \mathrm{m}, \mathrm{H}_{\text {aromatic }}, \mathrm{H}_{\text {thiazole }}\right), 9.68$ $\left(1 \mathrm{H}, \mathrm{s}, \mathrm{NH}\right.$ exchangeable with $\left.\mathrm{D}_{2} \mathrm{O}\right)$. MS: $(\mathrm{m} / \mathrm{z}) \sim$ $[\mathrm{M}+1]^{+} 481(8.5 \%)$.

Preparation of 2-(\{[4-(2-Hydrazinyl-1,3-thiazol4-yl)phenyl] amino methyl)-1H-isoindole1,3(2H)-dione (7)

A mixture of compound $1(0.75 \mathrm{~g}, 2 \mathrm{mmol})$ and thiosemicarbazide $(0.18 \mathrm{~g}, 2 \mathrm{mmol})$ in absolute ethanol $(15 \mathrm{ml})$ was heated under reflux for $4 \mathrm{hr}$. The reaction mixture was cooled, made alkaline using $10 \%$ sodium hydroxide solution $(1 \mathrm{ml})$, poured onto ice water and then acidified using hydrochloric acid. The formed precipitate was filtered off, washed with water, air dried and crystallized from dioxane, greenish brown crystals (Scheme 2), yield 69\%, mp 220-2 ${ }^{\circ} \mathrm{C}$. Analysis: for $\mathrm{C}_{18} \mathrm{H}_{15} \mathrm{~N}_{5} \mathrm{O}_{2} \mathrm{~S}$, M.Wt. 365.09, calculated: C: 58.16 H: $4.14 \mathrm{~N}: 19.17 \mathrm{~S}: 8.78$, found: C: 58.43 H: $4.33 \mathrm{~N}: 19.44 \mathrm{~S}: 8.85$. IR (KBr; $\left.\mathrm{cm}^{-1}\right): 3465$, $3350,3226\left(\mathrm{NH}_{2}, 2 \mathrm{NH}\right), 3059\left(\mathrm{CH}_{\text {aromatic }}\right), 2905$ $\left(\mathrm{CH}_{\text {alinhatic }}\right), 1770,1714(2 \mathrm{C}=\mathrm{O}), 1610(\mathrm{C}=\mathrm{N})$. ${ }^{1} \mathrm{H}$ NMR (DMSO, $\left.\delta \mathrm{ppm}\right): 3.13\left(2 \mathrm{H}, \mathrm{s}, \mathrm{NH}_{2}\right.$ exchangeable with $\left.\mathrm{D}_{2} \mathrm{O}\right), 5.00\left(2 \mathrm{H}, \mathrm{s}, \mathrm{CH}_{2}\right), 6.93-$ $7.95\left(9 \mathrm{H}, \mathrm{m}, \mathrm{H}_{\text {aromatic }}, \mathrm{H}_{\text {thiazole }}\right), 4.14,9.85(2 \mathrm{H}, 2 \mathrm{~s}$, $2 \mathrm{NH}$ exchangeable with $\left.\mathrm{D}_{2} \mathrm{O}\right)$. MS: $(\mathrm{m} / \mathrm{z}) \sim[\mathrm{M}]^{+}$ $365(10.3 \%)$.

General procedure for preparation of compounds $(8 a-d)$

A mixture of equimolecular amounts of compound $7(1 \mathrm{~g}, 2.7 \mathrm{mmol})$ and the appropriate aromatic aldehydes, namely, Vanillic aldehyde, veratraldehyde, 4-dimethylaminobenzaldehyde and 4-chlorobenzaldehyde $(2.7 \mathrm{mmol})$ in ethanol $(15 \mathrm{ml})$ was heated under reflux for $16-18 \mathrm{hr}$. The formed solid was filtered off and dried to give the title compounds 8a-d respectively (Scheme 2).

2-\{[(4-\{2-[-2-(4-Hydroxy-3-methoxybenzylidene)hydrazinyl]-1,3-thiazol-4-yl\} phenyl) amino]methyl\} -1H-isoindole-1,3(2H)-dione (8a)

Crystallized from dioxane, brown crystals, $\mathrm{mp}$ $210-2{ }^{\circ} \mathrm{C}$, yield $66 \%$. Analysis: for $\mathrm{C}_{26} \mathrm{H}_{21} \mathrm{~N}_{5} \mathrm{O}_{4} \mathrm{~S}$, M.Wt. 499.13, calculated: C: $62.51 \mathrm{H}: 4.24 \mathrm{~N}$ : 14.02 S: 6.42 found: C: $62.77 \mathrm{H}: 4.37 \mathrm{~N}: 13.78$ S: 6.56. IR (KBr; $\left.\mathrm{cm}^{-1}\right)$ : $3562-3324(\mathrm{OH}, 2 \mathrm{NH})$, $3039\left(\mathrm{CH}_{\text {aromatic }}\right), 2925\left(\mathrm{CH}_{\text {aliphatic }}\right), 1766,1709$ $(2 \mathrm{C}=\mathrm{O}), 1609(\mathrm{C}=\mathrm{N}) .{ }^{1} \mathrm{H}$ NMR (DMSO, $\left.\delta \mathrm{ppm}\right)$ : $3.84\left(3 \mathrm{H}, \mathrm{s}, \mathrm{OCH}_{3}\right), 5.17\left(2 \mathrm{H}, \mathrm{s}, \mathrm{CH}_{2}\right), 6.95-7.88$ $\left(13 \mathrm{H}, \mathrm{m}, \mathrm{H}_{\text {aromatic }}, \mathrm{HC}=\mathrm{N}, \mathrm{H}_{\text {thiazole }}\right), 5.63,9.77(2 \mathrm{H}$, $2 \mathrm{~s}, 2 \mathrm{NH}$ exchangeable with $\left.\mathrm{D}_{2} \mathrm{O}\right), 10.27(1 \mathrm{H}, \mathrm{s}$, $\mathrm{OH}$ exchangeable with $\left.\mathrm{D}_{2} \mathrm{O}\right)$. MS: $(\mathrm{m} / \mathrm{z}) \sim[\mathrm{M}]^{+}$ $499(2.6 \%)$.

2-\{[(4-\{2-[-2-(4,3-Dimethoxybenzylidene) hydrazinyl]-1,3-thiazol-4-yl\}phenyl)amino] methyl\}-1H-isoindole-1,3(2H)-dione (8b)

Crystallized from acetic acid, brown crystals, mp $187-9{ }^{\circ} \mathrm{C}$, yield 55\%. Analysis: for $\mathrm{C}_{27} \mathrm{H}_{23} \mathrm{~N}_{5} \mathrm{O}_{4} \mathrm{~S}$, M.Wt. 513.10, calculated: C: $63.14 \mathrm{H}: 4.51 \mathrm{~N}: 13.64 \mathrm{~S}: 6.24$ found: $\mathrm{C}: 63.46$ H: $4.67 \mathrm{~N}: 13.75 \mathrm{~S}: 6.40$. IR $\left(\mathrm{KBr} ; \mathrm{cm}^{-1}\right)$ : 3456, 3366 (2NH), $3065\left(\mathrm{CH}_{\text {aromatic }}\right), 2925\left(\mathrm{CH}_{\text {aliphatic }}\right)$, 1770, $1711(2 \mathrm{C}=\mathrm{O}), 1608(\mathrm{C}=\mathrm{N}) .{ }^{1} \mathrm{H}$ NMR (DMSO, $\delta$ ppm): $3.83\left(3 \mathrm{H}, \mathrm{s}, \mathrm{OCH}_{3}\right), 3.87(3 \mathrm{H}$, $\left.\mathrm{s}, \mathrm{OCH}_{3}\right), 5.14\left(2 \mathrm{H}, \mathrm{s}, \mathrm{CH}_{2}\right), 7.08-8.12(13 \mathrm{H}, \mathrm{m}$, $\left.\mathrm{H}_{\text {aromatic, }} \mathrm{HC}=\mathrm{N}, \mathrm{H}_{\text {thiazole }}\right), 5.65,9.84(2 \mathrm{H}, 2 \mathrm{~s}, 2 \mathrm{NH}$ exchangeable with $\left.\mathrm{D}_{2} \mathrm{O}\right) . \mathrm{MS}:(\mathrm{m} / \mathrm{z}) \sim[\mathrm{M}]^{+} 513$ $(2.3 \%)$

$2-\{[(4-\{2-[2-(4-\{$ Dime thylamino $\}$ benzylidene)hydrazinyl]-1,3-thiazol-4-yl\} phenyl) amino]methyl\}-1H-isoindole-1,3(2H)-dione (8c)

Crystallized from dioxane, brown crystals, $\mathrm{mp}$

Egypt. J. Chem. 60, No.4 (2017) 
178-9 ${ }^{\circ} \mathrm{C}$, yield $70 \%$. Analysis: for $\mathrm{C}_{27} \mathrm{H}_{24} \mathrm{~N}_{6} \mathrm{O}_{2} \mathrm{~S}$, M.Wt. 496.17, calculated: C: $65.30 \mathrm{H}: 4.87 \mathrm{~N}$ : $16.92 \mathrm{~S}: 6.46$ found: C: $65.04 \mathrm{H}: 4.98 \mathrm{~N}: 17.08$ S: 6.38. IR (KBr; $\left.\mathrm{cm}^{-1}\right): 3434,3372(2 \mathrm{NH}), 3065$ $\left(\mathrm{CH}_{\text {aromatic }}\right), 2923\left(\mathrm{CH}_{\text {aliphatic }}\right), 1771,1713(2 \mathrm{C}=\mathrm{O})$, $1596(\mathrm{C}=\mathrm{N}) .{ }^{1} \mathrm{H} \mathrm{NMR}(\mathrm{DMSO}, \delta \mathrm{ppm}): 3.01(6 \mathrm{H}$, $\left.\mathrm{s}, 2 \mathrm{CH}_{3}\right), 5.18\left(2 \mathrm{H}, \mathrm{s}, \mathrm{CH}_{2}\right), 6.73-8.05(14 \mathrm{H}, \mathrm{m}$, $\left.\mathrm{H}_{\text {aromatic }}, \mathrm{HC}=\mathrm{N}, \mathrm{H}_{\text {thiazole }}\right), 5.66,9.67(2 \mathrm{H}, 2 \mathrm{~s}, 2 \mathrm{NH}$ exchangeable with $\left.\mathrm{D}_{2} \mathrm{O}\right)$. MS: $(\mathrm{m} / \mathrm{z}) \sim[\mathrm{M}]^{+} 496$ (11.1\%).

$2-\{[(4-\{2-[2-(4-C h l o r o b e n z y l i d e n e)$ hydrazinyl]-1,3-thiazol-4-yl\}phenyl)amino] methyl\}-1H-isoindole-1,3(2H)-dione (8d)

Crystallized from dioxane, brown crystals, $\mathrm{mp}$ 237-9 ${ }^{\circ} \mathrm{C}$, yield $60 \%$. Analysis: for $\mathrm{C}_{25} \mathrm{H}_{18} \mathrm{ClN}_{5} \mathrm{O}_{2} \mathrm{~S}$, M.Wt. 487.09, calculated: C: $61.54 \mathrm{H}: 3.72 \mathrm{~N}$ : $7.27 \mathrm{~S}: 6.56$ found: $\mathrm{C}: 61.70 \mathrm{H}: 3.58 \mathrm{~N}: 7.13 \mathrm{~S}$ : 6.82. IR $\left(\mathrm{KBr} ; \mathrm{cm}^{-1}\right): 3456,3368(2 \mathrm{NH}), 3034$ $\left(\mathrm{CH}_{\text {aromatic }}\right), 2917\left(\mathrm{CH}_{\text {aliphatic }}\right), 1769,1708(2 \mathrm{C}=\mathrm{O})$, $1608(\mathrm{C}=\mathrm{N}) .{ }^{1} \mathrm{H}$ NMR (DMSO, $\left.\delta \mathrm{ppm}\right): 5.09$ $\left(2 \mathrm{H}, \mathrm{s}, \mathrm{CH}_{2}\right), 7.23-8.21\left(14 \mathrm{H}, \mathrm{m}, \mathrm{H}_{\text {aromatic }}, \mathrm{HC}=\mathrm{N}\right.$, $\left.\mathrm{H}_{\text {thiazole }}\right), 5.66,9.96(2 \mathrm{H}, 2 \mathrm{~s}, 2 \mathrm{NH}$ exchangeable with $\left.\mathrm{D}_{2} \mathrm{O}\right) . \mathrm{MS}:(\mathrm{m} / \mathrm{z}) \sim[\mathrm{M}]^{+} 487(1.9 \%), 489$ $(0.6 \%)$.

General procedure for preparation of compounds (9a,b)

A mixture of compounds $8 \mathrm{a}, \mathrm{c}(1 \mathrm{mmol})$ and triethylamine $(0.2 \mathrm{~g}, 2 \mathrm{mmol})$ was dissolved in dioxane $(0.5 \mathrm{ml})$ and cooled. To this cooled solution, acetyl chloride $(0.07 \mathrm{ml}, 1 \mathrm{mmol})$ was added slowly at $0{ }^{\circ} \mathrm{C}$. The mixture was stirred for $24 \mathrm{hr}$ and set aside for $48 \mathrm{hr}$ at room temperature. The formed solution was concentrated then the obtained product was poured on ice water. The separated solid was filtered off, washed with water and vacuum dried to give compounds 9a,b, respectively (Scheme 2).

2-(\{[4-(2-\{[4-(4-Hydroxy-3-methoxyphenyl)2-oxoazetidin-1-yl]amino\}-1,3-thiazol-4-yl) phenyl]amino\} methyl)-1H-isoindole-1,3(2H)dione (9a)

Crystallized from acetone, dark brown crystals, mp 196-8 ${ }^{\circ} \mathrm{C}$, yield $45 \%$. Analysis: for $\mathrm{C}_{28} \mathrm{H}_{23} \mathrm{~N}_{5} \mathrm{O}_{5} \mathrm{~S}$, M.Wt. 541.14, calculated: C: 62.10 $\mathrm{H}: 4.28 \mathrm{~N}$ : $12.93 \mathrm{~S}: 5.92$ found: C: $62.34 \mathrm{H}: 4.43$ $\mathrm{N}: 13.17 \mathrm{~S}: 5.84$. IR $\left(\mathrm{KBr} ; \mathrm{cm}^{-1}\right)$ : 3486-3365 $(\mathrm{OH}, 2 \mathrm{NH}), 3056\left(\mathrm{CH}_{\text {aromatic }}\right), 2934\left(\mathrm{CH}_{\text {aliphatic }}\right)$, 1772, 1711, $1665(3 \mathrm{C}=\mathrm{O}), 1605(\mathrm{C}=\mathrm{N}) \cdot{ }^{1} \mathrm{H}$ NMR (DMSO, $\delta$ ppm): 2.21-3.09 (2H, dd, $\mathrm{CH}_{2}-$ $\mathrm{C}=\mathrm{O}), 3.82\left(3 \mathrm{H}, \mathrm{s}, \mathrm{OCH}_{3}\right), 4.36(1 \mathrm{H}, \mathrm{t}, \mathrm{CH}-\mathrm{N})$, $5.10\left(2 \mathrm{H}, \mathrm{s}, \mathrm{CH}_{2}\right), 6.92-8.08\left(12 \mathrm{H}, \mathrm{m}, \mathrm{H}_{\text {aromatic' }}\right.$, $\left.\mathrm{H}_{\text {thiazole }}\right), 5.85,9.67(2 \mathrm{H}, 2 \mathrm{~s}, 2 \mathrm{NH}$ exchangeable with $\left.\mathrm{D}_{2} \mathrm{O}\right), 10.26(1 \mathrm{H}, \mathrm{s}, \mathrm{OH}$ exchangeable with $\left.\mathrm{D}_{2} \mathrm{O}\right) . \mathrm{MS}:(\mathrm{m} / \mathrm{z}) \sim[\mathrm{M}+1]^{+} 541(14.2 \%)$.

$2-(\{[4-(2-\{[4-(4-D i m e t h y l a m i n o p h e n y l)-2-$ oxoazetidin-1-yl]amino\}-1,3-thiazol-4-yl)phenyl] amino methyl)-1H-isoindole-1,3(2H)-dione (9b)

Crystallized from acetone, dark brown crystals, mp $162-4{ }^{\circ} \mathrm{C}$, yield $42 \%$. Analysis: for $\mathrm{C}_{29} \mathrm{H}_{26} \mathrm{~N}_{6} \mathrm{O}_{3} \mathrm{~S}$, M.Wt. 538.18, calculated: C: 64.67 $\mathrm{H}: 4.87 \mathrm{~N}: 15.60 \mathrm{~S}: 5.95$ found: C: $64.61 \mathrm{H}: 5.04 \mathrm{~N}$ : $15.83 \mathrm{~S}: 6.08$. IR (KBr; $\left.\mathrm{cm}^{-1}\right): 3445,3365(2 \mathrm{NH})$, $3093\left(\mathrm{CH}_{\text {aromatic }}\right), 2920\left(\mathrm{CH}_{\text {aliphatic }}\right), 1770,1712$, $1654(3 \mathrm{C}=\mathrm{O}), 1599(\mathrm{C}=\mathrm{N}) .{ }^{1} \mathrm{H}$ NMR $(\mathrm{DMSO}, \delta$ ppm): 2.35-3.12 (2H, dd, $\left.\mathrm{CH}_{2}-\mathrm{C}=\mathrm{O}\right), 3.01(6 \mathrm{H}, \mathrm{s}$, $\left.2 \mathrm{CH}_{3}\right), 4.22(1 \mathrm{H}, \mathrm{t}, \mathrm{CH}-\mathrm{N}), 5.23\left(2 \mathrm{H}, \mathrm{s}, \mathrm{CH}_{2}\right), 6.95-$ $7.96\left(13 \mathrm{H}, \mathrm{m}, \mathrm{H}_{\text {aromatic }}, \mathrm{H}_{\text {thiazole }}\right), 5.73,9.74(2 \mathrm{H}, 2 \mathrm{~s}$, $2 \mathrm{NH}$ exchangeable with $\left.\mathrm{D}_{2} \mathrm{O}\right) . \mathrm{MS}:(\mathrm{m} / \mathrm{z}) \sim[\mathrm{M}]^{+}$ $538(61.1 \%)$.

General procedure for preparation of compounds (10a,b)

A solution of chloroacetyl chloride $(0.13 \mathrm{~g}, 12$ $\mathrm{mmol})$ in dry dioxane was added dropwise below $10^{\circ} \mathrm{C}$ to a well stirred solution of compounds $8 a, c$ ( $1 \mathrm{mmol})$ and triethylamine $(0.3 \mathrm{~g}, 3 \mathrm{mmol})$. The reaction mixture was stirred for $6-7 \mathrm{hr}$, then the excess dioxane is removed and the residue was poured onto ice water, the resulting solid was filtered off, washed and vacuum dried to give compounds 10a,b (Scheme 2).

$2-(\{[4-(2-\{[3-$ Chloro-4-(4-hydroxy-3methoxyphenyl)-2-oxoazetidin-1-yl]amino\}-1,3thiazol-4-yl) phenyl] amino;methyl) -1H-isoindole -1,3(2H)-dione (10a)

Crystallized from acetone, dark brown crystals, mp 172-4 ${ }^{\circ} \mathrm{C}$, yield 50\%. Analysis: for $\mathrm{C}_{28} \mathrm{H}_{22} \mathrm{ClN}_{5} \mathrm{O}_{5} \mathrm{~S}$, M.Wt. 575.10, calculated: C: $58.38 \mathrm{H}: 3.85 \mathrm{~N}: 12.16 \mathrm{~S}: 5.57$ found: $\mathrm{C}$ : $58.56 \mathrm{H}: 4.04 \mathrm{~N}: 12.30 \mathrm{~S}: 5.72$. IR $\left(\mathrm{KBr} ; \mathrm{cm}^{-1}\right)$ : 3538-3325 (OH, 2NH), $3092\left(\mathrm{CH}_{\text {aromatic }}\right), 2956$ $\left(\mathrm{CH}_{\text {aliphatic }}\right), 1771,1714,1668(3 \mathrm{C}=\mathrm{O}), 1609$ $(\mathrm{C}=\mathrm{N}) \cdot{ }^{1} \mathrm{H}$ NMR (DMSO, $\left.\delta \mathrm{ppm}\right): 2.44(1 \mathrm{H}, \mathrm{d}$, $\mathrm{CH}-\mathrm{N}), 3.38(1 \mathrm{H}, \mathrm{d}, \mathrm{HC}-\mathrm{Cl}), 3.89\left(3 \mathrm{H}, \mathrm{s}, \mathrm{OCH}_{3}\right)$, $5.26\left(2 \mathrm{H}, \mathrm{s}, \mathrm{CH}_{2}\right), 7.12-7.98\left(12 \mathrm{H}, \mathrm{m}, \mathrm{H}_{\text {aromatic}}\right.$ ' $\left.\mathrm{H}_{\text {thiazole }}\right), 5.67,9.67(2 \mathrm{H}, 2 \mathrm{~s}, 2 \mathrm{NH}$ exchangeable with $\left.\mathrm{D}_{2} \mathrm{O}\right), 10.52(1 \mathrm{H}, \mathrm{s}, \mathrm{OH}$ exchangeable with $\left.\mathrm{D}_{2} \mathrm{O}\right)$. MS: $(\mathrm{m} / \mathrm{z}) \sim[\mathrm{M}-1]^{+} 575(31.3 \%)$.

2- $[(\{4-[2-(\{3-C h l o r o-4-[4-($ dimethylamino $)$ phenyl]-2-oxoazetidin-1-yl\}amino)-1,3-thiazol-4yl]phenyl\}amino)methyl]-1H-isoindole-1,3(2H)dione (10b)

Crystallized from dioxane, dark brown crystals, mp $176-7^{\circ} \mathrm{C}$, yield $55 \%$. Analysis: for $\mathrm{C}_{29} \mathrm{H}_{25} \mathrm{ClN}_{6} \mathrm{O}_{3} \mathrm{~S}$, M.Wt. 572.14, calculated: C: 
$60.78 \mathrm{H}: 4.40 \mathrm{~N}: 14.67 \mathrm{~S}: 5.60$ found: $\mathrm{C}: 60.96$ H: $4.29 \mathrm{~N}: 14.69 \mathrm{~S}: 5.38$. IR (KBr; $\left.\mathrm{cm}^{-1}\right)$ : 3456 , $3366(2 \mathrm{NH}), 3092\left(\mathrm{CH}_{\text {aromatic }}\right), 2919\left(\mathrm{CH}_{\text {aliphatic }}\right)$, 1773, 1711, $1673(3 \mathrm{C}=\mathrm{O}), 1606(\mathrm{C}=\mathrm{N}) .{ }^{1} \mathrm{H}$ NMR (DMSO, $\delta \mathrm{ppm}): 2.51(1 \mathrm{H}, \mathrm{d}, \mathrm{CH}-\mathrm{N}), 3.01(6 \mathrm{H}$, s, $\left.2 \mathrm{CH}_{3}\right), 3.10(1 \mathrm{H}, \mathrm{d}, \mathrm{HC}-\mathrm{Cl}), 5.16\left(2 \mathrm{H}, \mathrm{s}, \mathrm{CH}_{2}\right)$, 6.97-7.91 (13H, m, $\left.\mathrm{H}_{\text {aromatic }}, \mathrm{H}_{\text {thiazole }}\right), 5.64,9.63$ $\left(2 \mathrm{H}, 2 \mathrm{~s}, 2 \mathrm{NH}\right.$ exchangeable with $\left.\mathrm{D}_{2} \mathrm{O}\right)$. MS: $(\mathrm{m} / \mathrm{z}) \sim[\mathrm{M}]^{+} 572(8.1 \%)$.

General procedure for preparation of compounds $(11 a, b)$

A mixture of compounds $8 \mathrm{~b}, \mathrm{~d}(1 \mathrm{mmol})$ and thioglycolic acid $(0.2 \mathrm{ml}, 2 \mathrm{mmol})$ in benzene $(10 \mathrm{ml})$ was heated under reflux for 8-10 hr. The formed solid was filtered off and air dried to give compounds 11a,b, respectively (Scheme 2).

2-(\{[4-(2-\{[2-(3,4-Dimethoxyphenyl)-4-oxo1,3-thiazolidin-3-yl]amino\}-1,3-thiazol-4-yl) phenyl]amino\} methyl) -1H-isoindole -1,3(2H)dione (11a)

Crystallized from dioxane, brown crystals, mp $109-11^{\circ} \mathrm{C}$, yield $70 \%$. Analysis: for $\mathrm{C}_{29} \mathrm{H}_{25} \mathrm{~N}_{5} \mathrm{O}_{5} \mathrm{~S}_{2}$, M.Wt. 587.13, calculated: C: $59.27 \mathrm{H}: 4.29 \mathrm{~N}: 11.92 \mathrm{~S}: 10.91$ found: $\mathrm{C}: 59.54$ $\mathrm{H}: 4.45 \mathrm{~N}: 12.31 \mathrm{~S}: 10.78$. IR $\left(\mathrm{KBr} ; \mathrm{cm}^{-1}\right)$ : 3447 , 3369 (2NH), $3075\left(\mathrm{CH}_{\text {aromatic }}\right), 2927\left(\mathrm{CH}_{\text {aliphatic }}\right)$, 1772, 1711, $1660(3 \mathrm{C}=\mathrm{O}), 1612(\mathrm{C}=\mathrm{N}) .{ }^{1} \mathrm{H}$ NMR (DMSO, $\delta$ ppm): 3.15-3.29 $\left(2 \mathrm{H}, \mathrm{dd}, \mathrm{CH}_{2}\right.$ )$, 3.85\left(3 \mathrm{H}, \mathrm{s}, \mathrm{OCH}_{3}\right), 3.89(3 \mathrm{H}, \mathrm{s}$, $\left.\mathrm{OCH}_{3}\right), 4.16\left(1 \mathrm{H}, \mathrm{s}, \mathrm{CH}_{\text {thiazolidinone }}\right), 5.18(2 \mathrm{H}, \mathrm{s}$, $\left.\mathrm{CH}_{2}\right), 6.93-8.06\left(12 \mathrm{H}, \mathrm{m}, \mathrm{H}_{\text {aromatic }}, \mathrm{H}_{\text {thiazole }}\right), 5.66$, $9.65\left(2 \mathrm{H}, 2 \mathrm{~s}, 2 \mathrm{NH}\right.$ exchangeable with $\left.\mathrm{D}_{2} \mathrm{O}\right)$. MS: $(\mathrm{m} / \mathrm{z}) \sim[\mathrm{M}+2]^{+} 589(11.1 \%)$.

2-(\{[4-(2-\{[2-(4-Chlorophenyl)-4-oxo-1,3thiazolidin-3-yl]amino $\}-1,3-$ thiazol-4-yl) phenyl] amino\} methyl) -1H-isoindole -1,3(2H)- dione (11b)

Crystallized from acetic acid, brown crystals, mp $186-8{ }^{\circ} \mathrm{C}$, yield $60 \%$. Analysis: for $\mathrm{C}_{27} \mathrm{H}_{20} \mathrm{ClN}_{5} \mathrm{O}_{3} \mathrm{~S}_{2}$, M.Wt. 561.07, calculated: C: $57.70 \mathrm{H}: 3.59 \mathrm{~N}: 12.46 \mathrm{~S}: 11.41$ found: $\mathrm{C}: 57.59$ $\mathrm{H}: 3.71 \mathrm{~N}: 12.63 \mathrm{~S}: 11.80$. IR $\left(\mathrm{KBr} ; \mathrm{cm}^{-1}\right)$ : 3426 , 3345 (2NH), $3089(\mathrm{CH}), 2947\left(\mathrm{CH}_{\text {athatic }}\right)$, 1773, 1710, $1667(3 \mathrm{C}=\mathrm{O}), 1611(\mathrm{C}=\mathrm{N}) \cdot{ }^{1} \mathrm{H}$ NMR (DMSO, $\delta$ ppm): 3.20-3.35 $\left(2 \mathrm{H}, \mathrm{dd}, \mathrm{CH}_{2}\right.$ ), $4.14\left(1 \mathrm{H}, \mathrm{s}, \mathrm{CH}_{\text {thiazolidinone }}\right), 5.26(2 \mathrm{H}, \mathrm{s}$, $\left.\mathrm{CH}_{2}\right), 7.18-8.31\left(13 \mathrm{H}, \mathrm{m}, \mathrm{H}_{\text {aromatic }}, \mathrm{H}_{\text {thiazole }}\right), 5.64$, $9.87\left(2 \mathrm{H}, 2 \mathrm{~s}, 2 \mathrm{NH}\right.$ exchangeable with $\left.\mathrm{D}_{2} \mathrm{O}\right)$. MS: $(\mathrm{m} / \mathrm{z}) \sim[\mathrm{M}]^{+} 561(3.5 \%), 563(1.1 \%)$.

General procedure for preparation of compounds $(12 a, b)$

A mixture of compounds $8 \mathrm{~b}, \mathrm{~d}(1 \mathrm{~mol})$ and thiolactic acid $(0.2 \mathrm{ml}, 2 \mathrm{mmol})$ was fused at $140^{\circ} \mathrm{C}$ on sand bath for $6-8 \mathrm{hr}$. The solid mass was crystallized from the proper solvent to give the corresponding compounds $12 \mathrm{a}, \mathrm{b}$, respectively (Scheme 2).

2-(\{[4-(2-\{[5-Methyl-2-(3,4-dimethoxyphenyl)-4-oxo-1,3-thiazolidin-3-yl]amino\}1,3-thiazol-4-yl) phenyl] amino\} methyl)-1Hisoindole-1,3(2H)-dione (12a)

Crystallized from acetic acid, dark brown crystals, mp $138-40^{\circ} \mathrm{C}$, yield $65 \%$. Analysis: for $\mathrm{C}_{30} \mathrm{H}_{27} \mathrm{~N}_{5} \mathrm{O}_{5} \mathrm{~S}_{2}$, M.Wt. 601.15 , calculated: C: 59.88 H: $4.52 \mathrm{~N}: 11.64 \mathrm{~S}: 10.66$ found: C: 60.04 $\mathrm{H}: 4.67 \mathrm{~N}: 11.89 \mathrm{~S}: 10.51$. IR $\left(\mathrm{KBr} ; \mathrm{cm}^{-1}\right): 3459$, 3365 (2NH), $3081\left(\mathrm{CH}_{\text {aromatic }}\right), 2930\left(\mathrm{CH}_{\text {aliphatic }}\right)$, 1769, 1715, $1671(3 \mathrm{C}=\mathrm{O}), 1612(\mathrm{C}=\mathrm{N}) .{ }^{1} \mathrm{H}$ NMR (DMSO, $\delta \mathrm{ppm}): 1.41\left(3 \mathrm{H}, \mathrm{d}, \mathrm{CH}_{3 \text { thiazolidinone }}\right), 3.62$ $\left(1 \mathrm{H}, \mathrm{q}, \mathrm{CH}_{\text {thiazolidinone }}\right), 3.83\left(3 \mathrm{H}, \mathrm{s}, \mathrm{OCH}_{3}\right), 3.87$ $\left(3 \mathrm{H}, \mathrm{s}, \mathrm{OCH}_{3}\right), 4.97\left(1 \mathrm{H}, \mathrm{s}, \mathrm{CH}_{\text {thiazolidinne }}\right), 5.14$ $\left(2 \mathrm{H}, \mathrm{s}, \mathrm{CH}_{2}\right), 6.80-8.03\left(12 \mathrm{H}, \mathrm{m}, \mathrm{H}_{\text {aromatic }}, \mathrm{H}_{\text {thiazole }}\right)$, 7.88, $9.80\left(2 \mathrm{H}, 2 \mathrm{~s}, 2 \mathrm{NH}\right.$ exchangeable with $\left.\mathrm{D}_{2} \mathrm{O}\right)$. MS: $(\mathrm{m} / \mathrm{z}) \sim[\mathrm{M}+1]^{+} 602(64.5 \%)$.

2-(\{[4-(2-\{[5-Methyl-2-(4-chlorophenyl)-4oxo-1,3-thiazolidin-3-yl]amino\}-1,3-thiazol-4-yl) phenyl] amino\} methyl) -1H-isoindole -1,3(2H) -dione (12b)

Crystallized from acetic acid, dark brown crystals, mp $153-5{ }^{\circ} \mathrm{C}$, yield $60 \%$. Analysis: for $\mathrm{C}_{28} \mathrm{H}_{22} \mathrm{ClN}_{5} \mathrm{O}_{3} \mathrm{~S}_{2}$, M.Wt. 575.09, calculated: C: $58.38 \mathrm{H}: 3.85 \mathrm{~N}: 12.16 \mathrm{~S}: 11.13$ found: C: 58.50 H: $3.99 \mathrm{~N}: 11.98 \mathrm{~S}: 11.38$. IR $\left(\mathrm{KBr} ; \mathrm{cm}^{-1}\right)$ : 3436 , 3347 (2NH), 3094 ( $\mathrm{CH}$ aromatic $), 2927$ ( $\left.\mathrm{CH}_{\text {aliphatic }}\right)$, 1771, 1713, $1667(3 \mathrm{C}=\mathrm{O}), 1611(\mathrm{C}=\mathrm{N}) .{ }^{1} \mathrm{H}$ NMR (DMSO, $\delta$ ppm): $1.40\left(3 \mathrm{H}, \mathrm{d}, \mathrm{CH}_{3}\right.$ inizolidinone $), 3.62$ $(1 \mathrm{H}, \mathrm{q}, \mathrm{CH}$ thiazolidinone $), 4.40\left(1 \mathrm{H}, \mathrm{s}, \mathrm{CH}_{\text {thiazolidinone }}\right)$, $5.19\left(2 \mathrm{H}, \mathrm{s}, \mathrm{CH}_{2}\right), 7.00-7.97\left(13 \mathrm{H}, \mathrm{m}, \mathrm{H}_{\text {aromatic}}\right.$ ' $\left.\mathrm{H}_{\text {thiazole }}\right), 7.83,10.0(2 \mathrm{H}, 2 \mathrm{~s}, 2 \mathrm{NH}$ exchangeable with $\left.\mathrm{D}_{2} \mathrm{O}\right) . \mathrm{MS}:(\mathrm{m} / \mathrm{z}) \sim[\mathrm{M}]^{+} 575(8.1 \%), 577$ $(2.6 \%)$.

Preparation of Ethyl (4-\{[(1,3-dioxo-1,3dihydro-2H-isoindol-2-yl)methyl]amino , phenyl) (oxo)acetate (13)

To a solution of selenium dioxide $(0.34 \mathrm{~g}, 3$ $\mathrm{mmol})$ in absolute ethanol $(10 \mathrm{ml})$, compound $\mathbf{1}$ (0.75 g, 2 mmol) was added. The mixture was heated under reflux for $15 \mathrm{hr}$. The precipitated selenium metal was removed by filtration and the filtrate was evaporated and the residue was crystallized from ethanol, yellow crystals (Scheme 3), mp $134-6{ }^{\circ} \mathrm{C}$, yield $71 \%$. Analysis: for $\mathrm{C}_{10} \mathrm{H}_{16} \mathrm{~N}_{2} \mathrm{O}_{5}$, M.Wt. 352.11, calculated: C: $64.77 \mathrm{H}: 4.58 \mathrm{~N}: 7.95$, found: C: $64.89 \mathrm{H}: 4.50 \mathrm{~N}$ : 8.11. IR ( $\left.\mathrm{KBr} ; \mathrm{cm}^{-1}\right)$ : $3371(\mathrm{NH}), 3074\left(\mathrm{CH}_{\text {aromatic }}\right)$,

Egypt. J. Chem. 60, No.4 (2017) 
$2921\left(\mathrm{CH}_{\text {aliphatic }}\right), 1772,1716,1670(4 \mathrm{C}=\mathrm{O}) .{ }^{1} \mathrm{H}$ NMR (DMSO, $\delta \mathrm{ppm}): 1.41\left(3 \mathrm{H}, \mathrm{t}, \mathrm{CH}_{3}\right), 3.95$ $\left(2 \mathrm{H}, \mathrm{q}, \mathrm{OCH}_{2}\right), 5.24\left(2 \mathrm{H}, \mathrm{s}, \mathrm{CH}_{2}\right), 7.73-8.31(8 \mathrm{H}$, $\left.\mathrm{m}, \mathrm{H}_{\text {aromatic }}\right), 9.47(1 \mathrm{H}, \mathrm{s}, \mathrm{NH}$ exchangeable with $\left.\mathrm{D}_{2} \mathrm{O}\right)$.

Preparation of 2-(\{[4-(3-Oxo-3,4- dihydroquinoxalin -2-yl)phenyl] amino\} methyl)-1Hisoindole-1,3 (2H)-dione (14)

A solution of benzene-1,2-diamine ( $0.15 \mathrm{~g}, 1.4$ $\mathrm{mmol})$ in ethanol $(5 \mathrm{ml})$ was added to the solution of compound 13 (0.35 g, $1 \mathrm{mmol})$ in ethanol (10 $\mathrm{ml})$ and the mixture was heated on steam bath for $8 \mathrm{hr}$. The solution was diluted with water and the formed precipitate was filtered off, washed with cold alcohol, crystallized from ethanol, light yellow crystals (Scheme 3), mp 215-6 ${ }^{\circ} \mathrm{C}$, yield 68\%. Analysis: for $\mathrm{C}_{23} \mathrm{H}_{16} \mathrm{~N}_{4} \mathrm{O}_{3}$, M.Wt. 396.14, calculated: C: $69.69 \mathrm{H}: 4.07 \mathrm{~N}: 14.13$, found: C: 69.21 H: $4.31 \mathrm{~N}: 14.33$. IR $\left(\mathrm{KBr} ; \mathrm{cm}^{-1}\right): 3426$, $3323(2 \mathrm{NH}), 3091\left(\mathrm{CH}_{\text {aromatic }}\right), 2926\left(\mathrm{CH}_{\text {aliphatic }}\right)$, $1769,1715,1656 \quad(3 \mathrm{C}=\mathrm{O}), 1610 \quad(\mathrm{C}=\mathrm{N}) \cdot{ }^{1} \mathrm{H}$ NMR (DMSO, $\delta$ ppm): $5.49\left(2 \mathrm{H}, \mathrm{s}, \mathrm{CH}_{2}\right), 7.31-$ $8.20\left(12 \mathrm{H}, \mathrm{m}, \mathrm{H}_{\text {aromatic }}\right), 8.45,9.67(2 \mathrm{H}, 2 \mathrm{~s}, 2 \mathrm{NH}$ exchangeable with $\left.\mathrm{D}_{2} \mathrm{O}\right) . \mathrm{MS}:(\mathrm{m} / \mathrm{z}) \sim[\mathrm{M}-1]^{+} 395$ $(79.3 \%)$.

Preparation of 2-[(4-\{[(1,3-Dioxo-1,3dihydro-2H-isoindol-2-yl)methyl] amino phenyl) -2-oxoethyl] propanedinitrile (15)

A mixture of compound 1 (0.75 g, $2 \mathrm{mmol})$ and malononitrile $(0.13 \mathrm{~g}, 2 \mathrm{mmol})$ in absolute ethanol $(10 \mathrm{ml})$ was treated with sodium hydroxide solution ( $2 \mathrm{ml}, 40 \%)$ dropwise with stirring for about $10 \mathrm{~min}$. After complete addition, the reaction mixture was diluted with water $(5 \mathrm{ml})$. The formed precipitate was filtered off, washed several times with water and air dried to give compound 15, buff crystals (Scheme 3 ), mp 135$7{ }^{\circ} \mathrm{C}$, yield $65 \%$. Analysis: for $\mathrm{C}_{20} \mathrm{H}_{14} \mathrm{~N}_{4} \mathrm{O}_{3}, \mathrm{M}$.Wt. 358.11, calculated: C: $64.03 \mathrm{H}: 3.94 \mathrm{~N}: 15.63$, found: C: $64.35 \mathrm{H}: 4.11 \mathrm{~N}: 15.84$. IR (KBr; cm $\left.{ }^{1}\right): 3448(\mathrm{NH}), 3032\left(\mathrm{CH}_{\text {aromatic }}\right), 2925\left(\mathrm{CH}_{\text {aliphatic }}\right)$, $2199(2 \mathrm{C} \equiv \mathrm{N}), \quad 1774, \quad 1716,1667 \quad(3 \mathrm{C}=\mathrm{O}) .{ }^{1} \mathrm{H}$ NMR (DMSO, $\delta$ ppm): $2.96\left(2 \mathrm{H}, \mathrm{d}, \mathrm{CH}_{2}\right), 4.03$ $(1 \mathrm{H}, \mathrm{t}, \mathrm{CH}), 5.12\left(2 \mathrm{H}, \mathrm{s}, \mathrm{CH}_{2}\right), 7.33-8.30(8 \mathrm{H}$, $\left.\mathrm{m}, \mathrm{H}_{\text {aromatic }}\right), 9.58(1 \mathrm{H}, \mathrm{s}, \mathrm{NH}$ exchangeable with $\left.\mathrm{D}_{2} \mathrm{O}\right)$. MS: $(\mathrm{m} / \mathrm{z}) \sim[\mathrm{M}]^{+} 358(1 \%)$.

Preparation of 2-Amino-5-(4-\{[(1,3-dioxo-1,3dihydro-2H-isoindol-2-yl) methyl]amino? phenyl) furan-3-carbonitrile (16)

A solution of compound 15 (0.36 g, $1 \mathrm{~mol})$ in acetic acid $(5 \mathrm{ml})$ was heated under reflux with $0.5 \mathrm{ml}$ concentrated hydrochloric acid for $10 \mathrm{~h}$. The reaction mixture was cooled and diluted with water, and then the formed solid was filtered off, dried under vacuum and then crystallized from ethanol, light brown crystals (Scheme 3), mp $102-3{ }^{\circ} \mathrm{C}$, yield $75 \%$. Analysis: for $\mathrm{C}_{20} \mathrm{H}_{14} \mathrm{~N}_{4} \mathrm{O}_{3}$, M.Wt. 358.11, calculated: C: $64.03 \mathrm{H}: 3.94 \mathrm{~N}: 15.63$, found: $\mathrm{C}: 64.40 \mathrm{H}$ : $4.26 \mathrm{~N}: 15.41$. IR $\left(\mathrm{KBr} ; \mathrm{cm}^{-1}\right): 3435,3370$ $\left(\mathrm{NH}, \mathrm{NH}_{2}\right), 3023\left(\mathrm{CH}_{\text {aromatic }}\right), 2925\left(\mathrm{CH}_{\text {aliphatic }}\right)$, $2197(\mathrm{C} \equiv \mathrm{N}), 1771,1713(2 \mathrm{C}=\mathrm{O}) .{ }^{1} \mathrm{H}$ NMR (DMSO, $\delta$ ppm): $5.06\left(2 \mathrm{H}, \mathrm{s}, \mathrm{CH}_{2}\right), 4.80(2 \mathrm{H}$, $\mathrm{s}, \mathrm{NH}_{2}$ exchangeable with $\left.\mathrm{D}_{2} \mathrm{O}\right), 8.77(1 \mathrm{H}, \mathrm{s}$, $\mathrm{NH}$ exchangeable with $\left.\mathrm{D}_{2} \mathrm{O}\right), 6.57-8.19$ (m, $\left.9 \mathrm{H}, \mathrm{H}_{\text {aromatic }}, \mathrm{H}_{\text {furan }}\right)$.

General procedure for preparation of compounds $(17 a, b)$

To a solution of compound $15(0.36 \mathrm{~g}, 1$ $\mathrm{mmol})$ in ethanol $(8 \mathrm{ml})$, hydrazine hydrate or phenyl hydrazine $(1.5 \mathrm{mmol})$ was added. The reaction mixture was refluxed for 13-15 hr. The formed precipitate was then filtered off and air dried to give compounds $17 \mathrm{a}, \mathrm{b}$ (Scheme 3).

2-[(\{4-[(3,5-Diamino-1H-pyrazol-4-yl)acetyl] phenyl\}amino)methyl]-1H-isoindole-1,3(2H)dione (17a)

Crystallized from methanol, light brown crystals, mp $212-4{ }^{\circ} \mathrm{C}$, yield $55 \%$. Analysis: for $\mathrm{C}_{20} \mathrm{H}_{18} \mathrm{~N}_{6} \mathrm{O}_{3}$, M.Wt. 390.13, calculated: C: $61.53 \mathrm{H}: 4.65 \mathrm{~N}: 21.29$, found: $\mathrm{C}: 61.20 \mathrm{H}$ : $4.67 \mathrm{~N}: 21.57$. IR $\left(\mathrm{KBr} ; \mathrm{cm}^{-1}\right): 3438,3371$, $3168\left(2 \mathrm{NH}, 2 \mathrm{NH}_{2}\right), 3019\left(\mathrm{CH}_{\text {aromatic }}\right), 2898$ $\left(\mathrm{CH}_{\text {aliphatic }}\right), 1774,1720,1658(3 \mathrm{C}=\mathrm{O}), 1610$ $(\mathrm{C}=\mathrm{N}) .{ }^{1} \mathrm{H}$ NMR (DMSO, $\left.\delta \mathrm{ppm}\right): 3.02(2 \mathrm{H}, \mathrm{s}$, $\left.\mathrm{COCH}_{2}\right), 5.27\left(2 \mathrm{H}, \mathrm{s}, \mathrm{CH}_{2}\right), 7.03-7.89(8 \mathrm{H}, \mathrm{m}$, $\left.\mathrm{H}_{\text {aromatic }}\right), 5.69,8.75,9.63,10.74(6 \mathrm{H}, 4 \mathrm{~s}, 2 \mathrm{NH}$, $2 \mathrm{NH}_{2}$ exchangeable with $\left.\mathrm{D}_{2} \mathrm{O}\right) . \mathrm{MS}:(\mathrm{m} / \mathrm{z}) \sim$ $[\mathrm{M}+3]^{+} 393(19.4 \%)$.

2-[(\{4-[(3,5-Diamino-1-phenyl-pyrazol-4$y l$ acetyl]phenyl\}amino)methyl]-1H-isoindole1,3(2H)-dione $(17 b)$

Crystallized from ethanol, light brown crystals, mp $78-80{ }^{\circ} \mathrm{C}$, yield $65 \%$. Analysis: for $\mathrm{C}_{26} \mathrm{H}_{22} \mathrm{~N}_{6} \mathrm{O}_{3}$, M.Wt. 466.17, calculated: C: 66.94 $\mathrm{H}: 4.75 \mathrm{~N}$ : 18.02 , found: C: $66.58 \mathrm{H}: 4.96 \mathrm{~N}$ : 18.29. IR $\left(\mathrm{KBr} ; \mathrm{cm}^{-1}\right): 3467,3363,3220(\mathrm{NH}$, $\left.2 \mathrm{NH}_{2}\right), 3069\left(\mathrm{CH}_{\text {aromatic }}\right), 2922\left(\mathrm{CH}_{\text {aliphatic }}\right), 1773$, $1716,1660(3 \mathrm{C}=\mathrm{O}), 1603(\mathrm{C}=\mathrm{N}) \cdot{ }^{1} \mathrm{H}$ NMR (DMSO, $\delta \mathrm{ppm}): 2.90\left(2 \mathrm{H}, \mathrm{s}, \mathrm{COCH}_{2}\right), 5.18$ $\left(2 \mathrm{H}, \mathrm{s}, \mathrm{CH}_{2}\right), 7.24-8.10\left(13 \mathrm{H}, \mathrm{m}, \mathrm{H}_{\text {aromatic }}\right), 6.98$, $8.27,10.74\left(5 \mathrm{H}, 3 \mathrm{~s}, \mathrm{NH}, 2 \mathrm{NH}_{2}\right.$ exchangeable with $\mathrm{D}_{2} \mathrm{O}$ ).

\section{Antimicrobial evaluation}

Most of the newly synthesized compounds

Egypt. J. Chem. 60, No.4 (2017) 
were individually tested against highly pathogenic strains of gram positive (Staphylococcus aureus (ATCC 9213), Bacillus subtilis (ATCC 6633), Bacillus megaterium (ATCC 9885)) and gram negative (Klebsiella pneumonia (ATCC 13883), Pseudomonas aeruginosa (ATCC 27953), Escherichia coli (ATCC 25922)) bacterial pathogens, yeasts (Saccharomyces cerevisiae, Candida albicans (NRRLY-477) and fungus (Aspergillus niger (local isolate)) using $100 \mu \mathrm{l}$ of suspension containing $1 \times 10^{8}$ colony-forming unit/ $\mathrm{mL}(\mathrm{CFU} / \mathrm{ml})$ of pathological tested bacteria, 1 $\mathrm{x} 10^{6} \mathrm{CFU} / \mathrm{ml}$ of yeast and $1 \times 10^{6} \mathrm{CFU} / \mathrm{ml}$ of fungi spread on nutrient agar (NA), Sabourand dextrose agar (SDA) and Potato dextrose agar medium (PDA), respectively.

\section{Agar well diffusion assay}

Antimicrobial screening was carried out by the agar well diffusion method of Perez et al. [19]. After the preparation of nutrient agar media (sabourand dextrose agar (SDA) and potato dextrose agar medium (PDA) for bacteria and fungi, respectively), they were left to cool and solidify; $100 \mu \mathrm{L}$ of suspension containing $1 \times 10^{8}$ $\mathrm{CFU} / \mathrm{ml}$ of pathological tested bacteria, $1 \times 10^{6}$ $\mathrm{CFU} / \mathrm{ml}$ of fungi were spread on nutrient agar. Then, wells (10 $\mathrm{mm}$ in diameter) were made in the solidified agar and loaded with $100 \mu$ l of tested compound solutions [prepared by dissolving 100 $\mathrm{mg}$ of the chemical compound in $1 \mathrm{ml}$ of dimethyl sulfoxide (DMSO)]. The inculcated plates were then incubated for $24 \mathrm{hr}$ at $37{ }^{\circ} \mathrm{C}$ for bacteria and $48 \mathrm{hr}$ at $28^{\circ} \mathrm{C}$ for fungi. Negative controls were prepared using the solvent employed for dissolving the tested compound (DMSO). Ciprofloxacin $(50 \mathrm{mg} / \mathrm{ml})$ and Ketoconazole (50 $\mathrm{mg} / \mathrm{ml}$ ) were used as standard for antibacterial and antifungal activities, respectively. After the incubation time, the antimicrobial activity was evaluated by measuring the diameter $(\mathrm{mm})$ of the inhibition zone (IZ) of the selected compounds against the test organisms. The experiments were carried out in triplicate and the average inhibition zone was calculated (Table 1).

\section{Broth dilution method}

The bacteriostatic activity of the active compounds (IZ $\geq 16 \mathrm{~mm}$ ) was then evaluated using the two-fold serial dilution technique. [20] Two fold serial dilutions of the tested compounds solutions were prepared using the proper nutrient broth. The final concentrations of the solutions were 200, 100, 50, $25 \mathrm{mg} / \mathrm{ml}$. Each $5 \mathrm{ml}$ received $0.1 \mathrm{ml}$ of the appropriate inoculum and incubated at $37^{\circ} \mathrm{C}$ for $24 \mathrm{hr}$. The lowest concentration showing no growth was taken as MIC (Table 2).

\section{References}

1. Teo, S.K., Stirling, D.I., and Zeldis, J.B., Thalidomide as a novel therapeutic agent: new uses for an old product, Drug Discov Today, 10, 107-14 (2005).

2. Salvi, V. K., Bhambi, D., Jat, J. L. and Talesara, G. L., Synthesis and anti-microbial activity of some 2-[1-(4-oxo-3,4-dihydrophthalazine-1-yl)alkyl] $-1 H$-isoindole-1,3(2H)-dione and their imidoxy derivatives", ARKIVOC, (xiv), 133-140 (2006).

3. Bhambi, D., Salvi, V. K., Bapna, A., Pemawat, G. and Talesara, G. L., Synthesis and antimicrobial evaluation of some alkoxyphthalimide derivatives of naphthyridine, Indian J. Chem., 48B, 697-704 (2009).

4. Reddy, C.U.M., Jayakar, B. and Srinivasan, R., Synthesis and antimicrobial activity of a N-phthalimido and acetimido derivatives from amino acids and anhydrides, Inter. J. Pharma Bio Sci. 1, 81-86 (2010).

5. Sabastiyan, A. and Suvaikin, M. Y., Synthesis, characterization and anti-microbial activity of 2-(dimethylaminomethyl)isoindoline-1,3-dione and its cobalt(II) and nickel(II) complexes, $A d v$. Appl. Sci. Res. 3, 45-50 (2012).

6. Spallarossa, A., Cesarini, S., Ranise, A., Schenone, S., Bruno, O., Borassi, A., La Colla, P., Pezzullo, M., Sanna, G., Collu, G., Secci B. and Loddo R., Parallel synthesis, molecular modelling and further structure-activity relationship studies of new acylthiocarbamates as potent non-nucleoside $\mathrm{HIV}-1$ reverse transcriptase inhibitors, Eur. J. Med. Chem., 44, 2190-2201 (2009).

7. Yang, Y. J., Zhao, J. H., Pan, X. D. and Zhang, P. C., Synthesis and Antiviral Activity of Phthiobuzone Analogues, Chem. Pharm. Bull., 58, 208-211 (2010).

8. Chan, S. H., Lam, K. H., Chui, C. H., Gambari, R., Yuen, M. C. W., Wong, R. S. M., Cheng, G. Y. M., Lau, F. Y., Au, Y. K., Cheng, C. H., Lai, P.B.S.,Kan, C.W., Kok, S. H. L.,Tang, J. C. O. and Chan, A. S. C., The preparation and in vitro antiproliferative activity of phthalimide based ketones on MDAMB-231 and SKHep-1 human carcinoma cell lines, Eur. J. Med. Chem., 44, 2736-2740 (2009). 
9. Shiheido, H., Terada, F.,Tabata, N., Hayakawa, I., Matsumura, N., Takashima, H., Ogawa, Y., Du, W., Yamada, T., Shoji, M., Sugai, T., Doi, N., Iijima, S.,Hattori, Y. and Yanagawa, H., A., Phthalimide Derivative that Inhibits Centrosomal Clustering is Effective on Multiple Myeloma, PloS One Journal, doi: 10.1371/journal.pone.0038878 (2012).

10. Tetsuhashi, M., Ishikawa, M., Hashimoto, M., Hashimoto, Y. and Aoyama, H., Development of tryptase inhibitors derived from thalidomide, Bioorg. Med. Chem. 18, 5323-5338 (2010).

11. Palfreeman, A.C., McNamee, K. E. and McCann, F. E., New developments in the management of psoriasis and psoriatic arthritis: a focus on apremilast, Drug Des. Dev. Ther. 7, 201-210 (2013).

12. Iniaghe, L. O. and Usifoh, C. O., Anticonvulsant properties of $\mathrm{N}$-cyclopentyl phthalimide and N-benzylphthalimide, Res. J. Pharm. Biol. Chem. Sci., 1, 1068-1072 (2010).

13. Kamiński, K., Obniska, J., Wiklik, B. and Atamanyuk, D., Synthesis and anticonvulsant properties of new acetamide derivatives of phthalimide and its saturated cyclohexane and norbornene analogs, Eur. J. Med. Chem. 46, 46344641 (2011).

14. Yachide, T. N., Aoyama, A., Makishima, M., Miyachi, H. and Hashimoto, Y., Liver X receptor antagonists with a phthalimide skeleton derived from thalidomide-related glucosidase inhibitors, Bioorg. Med. Chem. Lett. 17, 3957-3961 (2007).

15. Motoshima, K., Yachide, T.N., Sugita, K., Hashimoto, Y. and Ishikawa, M., Separation of $\alpha$-glucosidase-inhibitory and liver $\mathrm{X}$ receptorantagonistic activities of phenethylphenyl phthalimide analogs and generation of LXR $\alpha$ selective antagonists, Bioorg. Med. Chem., 17, 5001-5014 (2009).

16. Motoshima, K., Sugita, K., Hashimoto, Y. and Ishikawa, M., Non-competitive and selective dipeptidyl peptidase IV inhibitors with phenethylphenyl phthalimide skeleton derived from thalidomide-related $\alpha$-glucosidase inhibitors and liver X receptor antagonists, Bioorg. Med. Chem. Lett. 21, 3041-3045 (2011).

17. Hassanzadeh, F., Rabbani, M., Khodarahmi, G. A., Fasihi, A., Hakimelahi, G. H. and Mohajeri, M., Synthesis of phthalimide derivatives and evaluation of their anxiolytic activity, Res. Pharm.
Sci., 2, 35-41 (2007).

18. Winstead, M.B. and Heine, H.W.,Identification of Amines. I. N-(Aryl-aminomethyl)-phthalimides, J. Am. Chem. Soc., 77, 1913-1914 (1955).

19. Perez, C.. Pauli, M. and Bazevque, P., An antibiotic assay by the agar well diffusion method, Acta. Biol. Med. Exp., 15, 113-115 (1990).

20. Scott, A. C., In Mackie and McCartney Practical Medical Microbiology Collee, J. G., 13 $3^{\text {th }}$ ed. Churchill Livingstone; Edinburgh, Scotland, UK, pp. 161-181(1989).

(Received:26/5/2016; accepted: 6/ 2 /2017) 


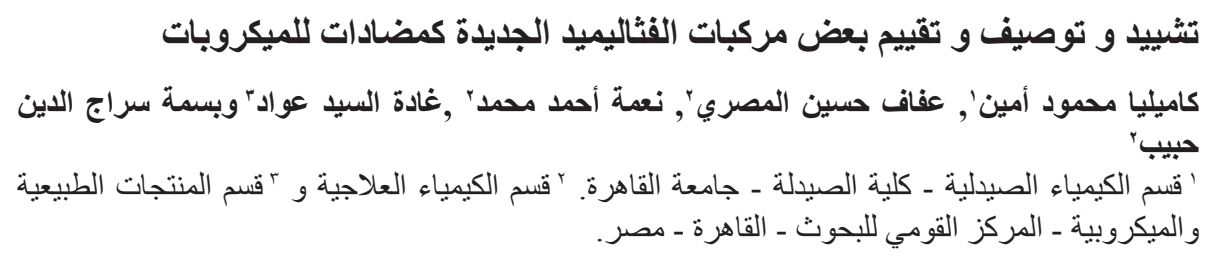

في محاو لة لتحضير مركبات جديدة مضادة للميكروبات، تم تشييد سلسلة جديدة من مشتقات -2 [2 [مشتقات الفينيل)

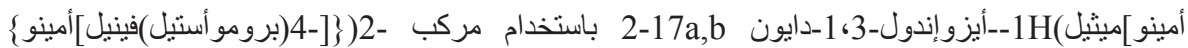

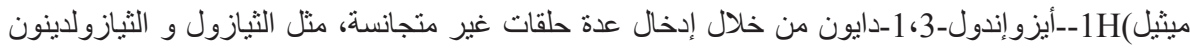

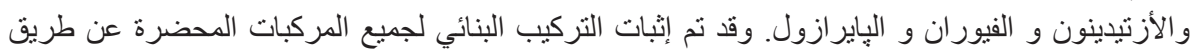

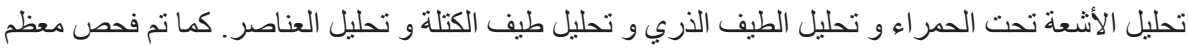

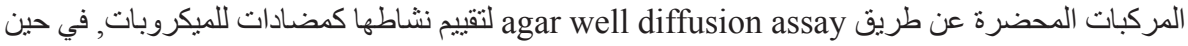
تم تقييم المركبات النشطة باستخدام broth dilution method لتحديد أقل تركيز لها مثبط للميكروبات.

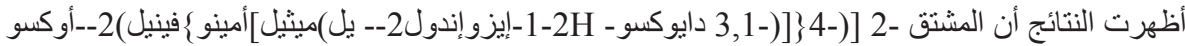
إيثيل]بروبإن داينتر ايل 15 هو المركب الأكثر فعالية. 